\title{
Modelos Black-Litterman e GARCH ortogonal para uma carteira de títulos do Tesouro Nacional
}

\author{
Roberto Beier Lobarinhas
}

\author{
DisSERTAÇÃO APRESENTADA \\ AO \\ Instituto De MatemáticA E EstatísticA \\ DA \\ Universidade DE SÃo PAUlo \\ PARA \\ OBTENÇÃO DO TÍTULO \\ DE \\ Mestre em CiÊnCIAS \\ Programa: Estatística \\ Orientador: Prof. Dr. Pedro Alberto Morettin
}

São Paulo, março de 2012 


\section{Modelos Black-Litterman e GARCH ortogonal para uma carteira de títulos do Tesouro Nacional}

Esta versão definitiva da dissertação contém as correções e alterações sugeridas pela Comissão Julgadora durante a defesa realizada por Roberto Beier Lobarinhas em 02/03/2012.

Comissão Julgadora:

- Prof. Dr. Pedro Alberto Morettin (orientador) - IME-USP

- Profa. Dra. Airlane Pereira Alencar - IME-USP

- Prof. Dr. Ernesto Coutinho Colla - FGV-SP 


\section{Agradecimentos}

Em primeiro lugar, gostaria de agradecer ao meu caro Professor Dr. Pedro Alberto Morettin que, com muita paciência, me ensinou, orientou e conduziu este trabalho.

Agradeço à minha família, que é a grande responsável por todas as minhas realizações. Em especial à minha esposa, Han, que sempre está ao meu lado.

Gostaria também de fazer uma homenagem ao meu lindo filho Theo, cuja vinda à nossa família nos enche de alegria e amor.

Agradeço aos amigos de mestrado Maurício Mazo, Manuel González, Mirian de Souza e Tiago Maia, que foram verdadeiros companheiros ao longo do mestrado, e aos colegas do Tesouro, pelas contribuições.

Agradeço também pelas valiosas contribuições do amigo e professor José Euclides, que generosamente sempre coloca seu conhecimento à disposição.

À Secretaria do Tesouro Nacional, por ter me dado a oportunidade de fazer este mestrado.

"Believe those who are seeking the truth. Doubt those who find it." Andre Gide (1947 nobel prize for literature, 1869-1951) 


\section{Resumo}

\section{Modelos Black-Litterman e GARCH ortogonal para uma carteira de títulos do Tesouro Nacional}

Uma grande dificuldade da gestão financeira é conseguir associar métodos quantitativos às formas tradicionais de gestão, em um único arranjo. O estilo tradicional de gestão tende a não crer, na devida medida, que métodos quantitativos sejam capazes de captar toda sua visão e experiência, ao passo que analistas quantitativos tendem a subestimar a importância do enfoque tradicional, gerando flagrante desarmonia e ineficiência na análise de risco. Um modelo que se propõe a diminuir a distância entre essas visões é o modelo Black-Litterman. Mais especificamente, propõe-se a diminuir os problemas enfrentados na aplicação da teoria moderna de carteiras e, em particular, os decorrentes da aplicação do modelo de Markowitz.

O modelo de Markowitz constitui a base da teoria de carteiras há mais de meio século, desde a publicação do artigo Portfolio Selection [Mar52], entretanto, apesar do papel de destaque da abordagem média-variância para o meio acadêmico, várias dificuldades aparecem quando se tenta utilizá-lo na prática, e talvez, por esta razão, seu impacto no mundo dos investimentos tem sido bastante limitado.

Apesar das desvantagens na utilização do modelo de média-variância de Markowitz, a idéia de maximizar o retorno, para um dado nível de risco é tão atraente para investidores, que a busca por modelos com melhor comportamento continuou e é neste contexto que o modelo Black-Litterman surgiu. Em 1992, Fischer Black e Robert Litterman publicam o artigo Portfolio Optimization [Bla92], fazendo considerações sobre o papel de pouco destaque da alocação quantitativa de ativos, e lançam o modelo conhecido por Black-Litterman.

Uma grande diferença entre o modelo Black-Litterman e um modelo média-variância tradicional é que, enquanto o segundo gera pesos em uma carteira a partir de um processo de otimização, o modelo Black-Litterman parte de uma carteira de mercado em equilíbrio de longo prazo (CAPM). Outro ponto de destaque do modelo é ser capaz de fornecer uma maneira clara para que investidores possam expressar suas visões de curto prazo e, mais importante, fornece uma estrutura para combinar de forma consistente a informação do equilíbrio de longo prazo (priori) com a visão do investidor (curto prazo), gerando um conjunto de retornos esperados, a partir do qual os pesos em cada ativo são fornecidos.

Para a escolha do método de estimação dos parâmetros, levou-se em consideração o fato de que 
matrizes de grande dimensão têm um papel importante na avaliação de investimentos, uma vez que o risco de uma carteira é fundamentalmente determinado pela matriz de covariância de seus ativos. Levou-se também em consideração que seria desejável utilizar um modelo flexível ao aumento do número de ativos. Um modelo capaz de cumprir este papel é o GARCH ortogonal, pois este pode gerar matrizes de covariâncias do modelo original a partir de algumas poucas volatilidades univariadas, sendo, portanto, um método computacionalmente bastante simples. De fato, as variâncias e correlações são transformações de duas ou três variâncias de fatores ortogonais obtidas pela estimação GARCH. Os fatores ortogonais são obtidos por componentes principais.

A decomposição da variância do sistema em fatores de risco permite quantificar a variabilidade que cada fator de risco traz, o que é de grande relevância, pois o gestor de risco poderá direcionar mais facilmente sua atenção para os fatores mais relevantes. Ressalta-se também que a ideia central da ortogonalização é utilizar um espaço reduzido de componentes. Neste modelo de dimensão reduzida, suficientes fatores de risco serão considerados, assim, os demais movimentos, ou seja, aqueles não capturados por estes fatores, serão considerados ruídos insignificantes para este sistema. Não obstante, a precisão, ao desconsiderar algumas componentes, irá depender de o número de componentes principais ser suficiente para explicar grande parte da variação do sistema. Logo, o método funcionará melhor quando a análise de componentes principais funcionar melhor, ou seja, em estruturas a termo e outros sistemas altamente correlacionados. Cabe mencionar que o GARCH ortogonal continua igualmente útil e viável quando pretende-se gerar matriz de covariâncias de fatores de risco distintos, isto é, tanto dos altamente correlacionados, quanto daqueles pouco correlacionados. Neste caso, basta realizar a análise de componentes principais em grupos correlacionados. Feito isto, obtêm-se as matrizes de covariâncias utilizando a estimação GARCH. Em seguida faz-se a combinação de todas as matrizes de covariâncias, gerando a matriz de covariâncias do sistema original.

A estimação GARCH foi escolhida pois esta é capaz de captar os principais fatos estilizados que caracterizam séries temporais financeiras. Entende-se por fatos estilizados padrões estatísticos observados empiricamente, que, acredita-se serem comuns a um grande número de séries temporais. Séries financeiras com suficiente alta frequência (observações intraday e diárias) costumam apresentar tais características. Este modelo foi utilizado para a estimação dos retornos e, com isso, obtivemos todas as estimativas para que, com o modelo B-L, pudéssemos gerar uma carteira ótima em um instante de tempo inicial. Em seguida, faremos previsões, obtendo carteiras para as semanas seguintes. Por fim, mostraremos que a associação do modelo B-L e da estimação GARCH ortogonal pode gerar resultados bastante satisfatórios e, ao mesmo tempo, manter o modelo simples e gerar resultados coerentes com a intuição.

Este estudo se dará sobre retornos de títulos de renda fixa, mais especificamente, títulos emitidos pelo Tesouro Nacional no mercado brasileiro. Tanto a escolha do modelo B-L, quanto a escolha por utilizar uma carteira de títulos emitidos pelo Tesouro Nacional tiveram como motivação o objetivo de aproximar ferramentas estatísticas de aplicações em finanças, em particular, títulos públicos federais emitidos em mercado, que têm se tornado cada vez mais familiares aos investidores pessoas físicas, sobretudo através do programa Tesouro Direto. Ao fazê-lo, espera-se que este estudo traga 
informações úteis tanto para investidores, quanto para gestores de dívida, uma vez que o modelo média-variância presta-se tanto àqueles que adquirem títulos, buscando, portanto, maximizar retorno para um dado nível de risco, quanto para aqueles que emitem títulos, e que, portanto, buscam reduzir seus custos de emissão a níveis prudenciais de risco.

Palavras-chave: Séries Temporais, Black-Litterman, Tesouro Nacional, Markowitz, Média-Variância, Alocação de Ativos, GARCH Ortogonal, Renda-Fixa . 


\section{Abstract}

\section{Black-Litterman and ortogonal GARCH models for a portfolio of bonds issued by the National Treasury}

One major challenge to financial management resides in associating traditional management with quantitative methods. Traditional managers tend to be skeptical about the quantitative methods' contributions, whereas quantitative analysts tend to disregard the importance of the traditional view, creating clear disharmony and inefficiency in the risk management process. A model that seeks to diminish the distance between these two views is the Black-Litterman model (BLM). More specifically, it comes as a solution to difficulties faced when using modern portfolio in practice, particularly those derived from the usage of the Markowitz model.

Although the Markowitz model has constituted the basis of portfolio theory for over half century, since the publication of the article Portfolio Selection [Mar52], its impact on the investment world has been quite limited. The Markowitz model addresses the most central objectives of an investment: maximizing the expected return, for a given level of risk. Even though it has had a standout role in the mean-average approach to academics, several difficulties arise when one attempts to make use of it in practice.

Despite the disadvantages of its practical usage, the idea of maximizing the return for a given level of risk is so appealing to investors, that the search for models with better behavior continued, and is in this context that the Black-Litterman model came out. In 1992, Fischer Black and Robert Litterman wrote an article on the Black-Litterman model.

One intrinsic difference between the BLM and a traditional mean-average one is that, while the second provides the weights of the assets in a portfolio out of a optimization routine, the BLM has its starting point at the long-run equilibrium market portfolio(CAPM). Another highlighting point of the BLM is the ability to provide one clear structucture that is able to combine the long term equilibrium information with the investor's views, providing a set of expected returns, which, together, will be the input to generate the weights on the assets.

As far as the estimation process is concerned, and for the purpose of choosing the most appropriate model, it was taken into consideration the fact that the risk of a portfolio is determined by the covariation matrix of its assets and, being so, matrices with large dimensions play an important role in the analysis of investments. Whereas, provided the application under study, it is desirable to have a model that is able to carry out the analysis for a considerable number of assets. For these reasons, the Orthogonal GARCH was selected, once it can generate the matrix of covariation of the 
original system from just a few univariate volatilities, and for this reason, it is a computationally simple method. The orthogonal factors are obtained with principal components analysis.

Decomposing the variance of the system into risk factors is highly important, once it allows the risk manager to focus separately on each relevant source of risk. The main idea behind the orthogonalization consists in working with a reduced dimension of components. In this kind of model, sufficient risk factors are considered, thus, the variability not perceived by the model will be considered insigficant noise to the system. Nevertheless, the precision, when not using all the components, will depend on the number of components be sufficient to explain the major part of the variability. Moreover, the model will provide reasonable results depending on principal component analysis performing properly as well, what will be more likely to happen, in highly correlated systems.

It is worthy of note that the Orthogonal GARCH is equally useful and feasible when one intends to analyse a portfolio consisting of assets across various types of risk, it means, a system which is not highly correlated. It is common to have such a portfolio, with, for instance, currency rates, stocks, fixed income and commodities. In order to make it to perform properly, it is necessary to separate groups with the same kind of risk and then carry out the principal component analysis by group and then merge the covariance matrices, producing the covariance matrix of the original system.

To work together with the orthogonalization method, the GARCH model was chosen because it is able to draw the main stylized facts which characterize financial time series. Stylized facts are statistical patterns empirically observed, which are believed to be present in a number of time series. Financial time series which sufficient high frequency (intraday, daily and even weekly) usually present such behavior.

For estimating returns purposes, it was used a ARMA model, and together with the covariance matrix estimation, we have all the parameters needed to perform the BLM study, coming out, in the end, with the optimal portfolio in a given initial time. In addition, we will make forecasts with the GARCH model, obtaining optimal portfolio for the following weeks. We will show that the association of the BLM with the Orthogonal GARCH model can generate satisfactory and coherent with intuition results and, at the same time, keeping the model simple.

Our application is on fixed income returns, more specifically, returns of bonds issued in the domestic market by the Brazilian National Treasury. The motivation of this work was to put together statistical tolls and finance uses and applications, more specifically those related to the bonds issued by the National Treasuy, which have become more and more popular due to the "Tesouro Direto" program. In conclusion, this work aims to bring useful information either for investors or to debt managers, once the mean-variance model can be useful for those who want to maximize return at a given level or risk as for those who issue bonds, and, thus, seek to reduce their issuance costs at prudential levels of risk. 
Keywords: Time Series, Black-Litterman, National Treasury, Markowtiz, Mean-Average, Asset Allocation, Orthogonal GARCH, Fixed Income. 


\section{Sumário}

Lista de Abreviaturas $\quad$ xiii

Lista de Símbolos $\quad$ XV

Lista de Figuras $\quad$ xvii

Lista de Tabelas $\quad$ xix

1 Introdução $\quad 1$

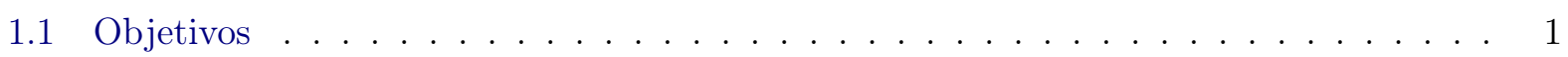

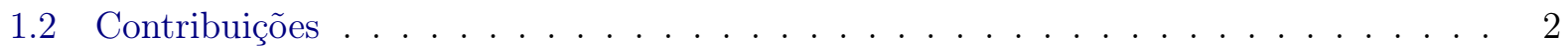

1.3 Organização do Trabalho . . . . . . . . . . . . . . . . . . . . . . . . 2

2 Modelo Black-Litterman $\quad 3$

2.1 Motivação: O Modelo Markowitz de Média-Variância . . . . . . . . . . . . . . . . 3

2.2 O Modelo . . . . . . . . . . . . . . . . . . . . . . . . . 4

2.2 .1 Introdução . . . . . . . . . . . . . . . . . . . . . 4

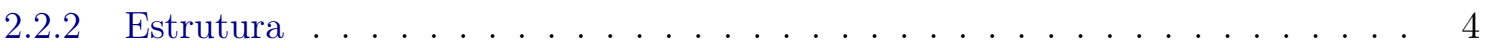

3 Carteira de Títulos do Tesouro Nacional 9

3.1 Motivação . . . . . . . . . . . . . . . . . . . . . . . . . . . 9

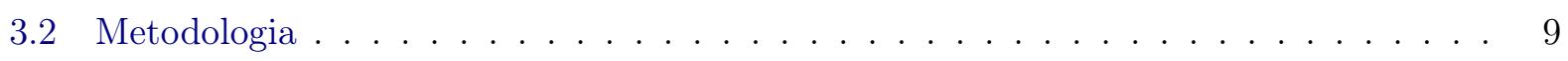

3.3 Séries Temporais . . . . . . . . . . . . . . . . . . . . . . 10

4 Modelo GARCH Ortogonal $\quad 17$

4.1 Introdução . . . . . . . . . . . . . . . . . . . . . . . . . . 17

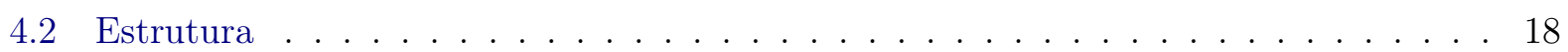

4.3 Vários Fatores de Risco . . . . . . . . . . . . . . . . . . . . . . . . 19

4.4 Estimação GARCH . . . . . . . . . . . . . . . . . . . . . . . . . . . . 20

5 Aplicação $\quad 23$

5.1 Modelo GARCH Ortogonal . . . . . . . . . . . . . . . . . . . . 23

5.1 .1 Componentes Principais . . . . . . . . . . . . . . . 23

5.1 .2 Ajuste do modelo GARCH . . . . . . . . . . . . . . . . 25

5.2 Black-Litterman . . . . . . . . . . . . . . . . . . . . . . 33

5.2 .1 Visões Subjetivas . . . . . . . . . . . . . . . . . 33

5.2 .2 Visões A Partir de um Modelo GARCH Ortogonal . . . . . . . . . . . . . . 35 
xii SUMÁRIO

5.2 .3 Resultados . . . . . . . . . . . . . . . . . . 36

6 Conclusões $\quad 41$

6.1 Sugestões para Pesquisas Futuras . . . . . . . . . . . . . . . . . . . 42

A Parâmetros da distribuição posteriori do modelo Black-Litterman 43

B Transformação para $\Omega$ não Diagonal $\quad 45$

$\begin{array}{ll}\text { Referências Bibliográficas } & 47\end{array}$

$\begin{array}{ll}\text { Índice Remissivo } & 48\end{array}$ 


\title{
Lista de Abreviaturas
}

\author{
B-L Black-Litterman \\ BLM Modelo Black-Litterman (Black-Litterman Model) \\ CAPM (Capital Asset Pricing Model) \\ MV Média-Variância (Mean-Average)
}




\section{Lista de Símbolos}

$\omega \quad$ Composição da carteira

$\Omega \quad$ Matriz de covariâncias da visão do investidor

$\delta \quad$ Coeficiente de aversão a risco

$\Pi \quad$ Retorno esperado

$\Sigma \quad$ Matriz de covariâncias dos retornos

$\mu \quad$ Média dos retornos

$r \quad$ Retornos

$\Sigma_{\pi} \quad$ Matriz de covariâncias de $\mu$

$\Sigma_{r} \quad$ Matriz de covariâncias dos retornos, considerando que $\mu$ também é uma variável aleatória

$\tau \quad$ Constante de proporcionalidade

$P \quad$ Combinações lineares das carteiras que compõem a informação que atualiza a a priori

$Q \quad$ Retornos das carteiras que compões a informação que atualiza a a priori

$A \quad$ Informação a priori

$B \quad$ Informação que atualiza a priori 


\section{Lista de Figuras}

3.1 Retornos das séries. . . . . . . . . . . . . . . . . . . . . . . . . . 12

3.2 Histogramas com normal ajustada. . . . . . . . . . . . . . . . . 13

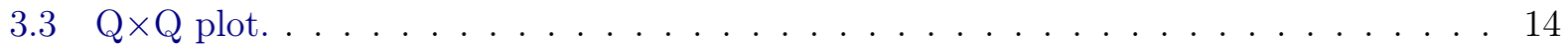

3.4 Números índices das séries. . . . . . . . . . . . . . . . . . . . . . . . . 15

5.1 Séries no espaço das componentes duas a duas. . . . . . . . . . . . . . . . . 24

5.2 Séries no espaço das três primeiras compoentes. . . . . . . . . . . . . . . . . 25

5.3 Função de autocorrelação parcial dos retornos e dos retornos ao quadrado da com-

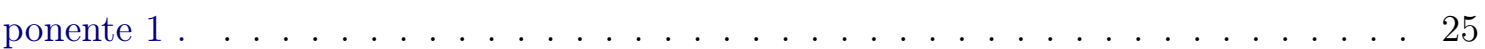

5.4 Função de autocorrelação e autocorrelação parcial dos resíduos ao quadrado do ajuste da componente $1 \ldots \ldots \ldots \ldots \ldots \ldots$

5.5 Função de autocorrelação parcial dos retornos ao quadrado da componente 2 . . . . . 27

5.6 Função de autocorrelação e autocorrelação parcial dos resíduos ao quadrado do ajuste da componente $2 \ldots \ldots \ldots \ldots \ldots \ldots \ldots \ldots$

5.7 Função de autocorrelação parcial dos retornos e dos retornos ao quadrado da componente $3 \ldots \ldots \ldots \ldots \ldots \ldots \ldots \ldots \ldots$

5.8 Função de autocorrelação e autocorrelação parcial dos resíduos ao quadrado do ajuste da componente $3 \ldots \ldots \ldots \ldots \ldots$

5.9 Função de autocorrelação parcial dos retornos e dos retornos ao quadrado da componente $4 \ldots \ldots \ldots \ldots \ldots \ldots \ldots$

5.10 Função de autocorrelação e autocorrelação parcial dos resíduos ao quadrado do ajuste

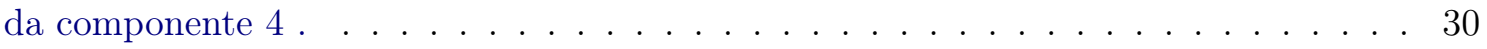

5.11 Variâncias estimadas das variáveis originais pelo modelo GARCH ortogonal . ... 30

5.12 Correlações estimadas pelo modelo GARCH ortogonal de cada uma das variáveis originais em relação às demais. . . . . . . . . . . . . . . . . . . . . . . . 31

5.13 Variâncias Estimadas Diretamente e pelo Método Ortogonal. . . . . . . . . . . . . . 32

5.14 Comparação do retorno e da composição da carteira antes e após incorporar visão subjetiva do investidor. . . . . . . . . . . . . . . . . . 35

5.15 Carteira de longo-prazo (o) e carteira ótima (+) após incorporar visões de curto-prazo do investidor. . . . . . . . . . . . . . . . . . . . . . 35

5.16 Fronteira eficiente da previsão $275 \ldots \ldots \ldots$. . . . . . . . . . . . . . 37

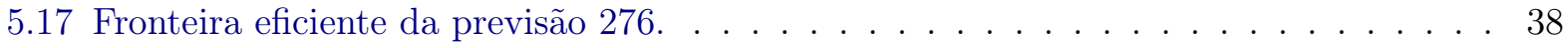

5.18 Fronteira eficiente da previsão $277 \ldots \ldots \ldots$

5.19 Fronteira eficiente da previsão $278 \ldots \ldots$. . . . . . . . . . . . . . . . . 39 
5.20 Índice Sharpe das carteiras geradas por um modelo GARCH e da carteira de mercado. 39 


\section{Lista de Tabelas}

3.1 Composição da carteira de mercado. . . . . . . . . . . . . . . . . . . . . . . . 10

3.2 Curtose das séries. . . . . . . . . . . . . . . . . . . . . . . . . . . . . . 11

3.3 Assimetria das séries. . . . . . . . . . . . . . . . . . . . 11

5.1 Variância explicada pelas componentes. . . . . . . . . . . . . . . . 23

5.2 Pesos das componentes. . . . . . . . . . . . . . . . . . . 24

5.3 Parâmetros do ajuste da componente $1 \ldots \ldots \ldots \ldots \ldots \ldots$

5.4 Parâmetros do ajuste da componente $2 \ldots \ldots \ldots \ldots \ldots \ldots$

5.5 Parâmetros do ajuste da componente $3 \ldots \ldots \ldots$. . . . . . . . . . . . . . 29

5.6 Parâmetros do ajuste da componente $4 \ldots \ldots$. . . . . . . . . . . 30 


\section{Capítulo 1}

\section{Introdução}

O estilo tradicional de gestão tende a não crer, na devida medida, que métodos quantitativos sejam capazes de captar toda sua visão e experiência, ao passo que analistas quantitativos tendem a subestimar a importância do enfoque tradicional, trazendo dificuldades à análise de risco e outras áreas de finanças.

Seja pela falta de intuição em seus resultados, seja pelo comportamento, muitas vezes indesejado, o modelo de Markowitz não é exceção às dificuldades mencionadas. Apesar de ter constituído a base da teoria de carteiras há mais de meio século, desde a publicação do artigo Portfolio Selection [Mar52], seu impacto no mundo dos investimentos tem sido bastante limitado. Em 1992, Fischer Black and Robert Litterman publicam o artigo Portfolio Optimization [Bla92] fazendo considerações sobre o papel de pouco destaque da alocação quantitativa de ativos, e lançam o modelo conhecido por Black-Litterman, que se propõe a diminuir a distância entre as visões quantitativa e tradicional, diminuindo os problemas enfrentados na aplicação da teoria moderna de carteiras e, em particular, os decorrentes da aplicação do modelo de Markowitz. O modelo Black-Litterman, entretanto, apesar de sua funcionalidade em conciliar métodos quantitativos e visões intuitivas do gestor de carteiras, tem seu uso ainda limitado no mundo das finanças. Um dos objetivos deste trabalho é trazer contribuições ao uso prático do modelo Black Litterman.

Outro objetivo deste trabalho é utilizar séries temporais para modelar o comportamento de séries financeiras, mais especificamente o comportamento de retornos de ativos de renda fixa. Para a aplicação, escolhemos títulos do Tesouro Nacional, conforme detalharemos mais à frente. Tendo-se em vista a natureza dos ativos selecionados, utilizaremos o modelo Garch Ortogonal para a estimação dos parâmetros, conforme discutiremos no Capítulo 4. Sem dúvida, mostrar ser possível estimar parâmetros para o modelo Black-Litterman, através da utilização de séries temporais foi a mais importante motivação deste trabalho.

Por fim estudaremos os resultados obtidos com o modelo Black-Litterman para esta particular aplicação de montar uma carteira ótima com títulos do Tesouro Nacional. Ao fazê-lo, espera-se que este estudo traga informações úteis tanto para investidores, quanto para gestores de dívida, uma vez que o modelo média-variância presta-se tanto para aqueles que adquirem títulos, buscando, portanto, maximizar retorno para um dado nível de risco, quanto para aqueles que emitem títulos, e que, portanto, buscam reduzir seus custos de emissão a níveis prudenciais de risco. Se este trabalho puder trazer contribuições a investidores e a emissores de dívida, que venham a estudar o assunto, este trabalho terá atingido plenamente seus objetivos.

\subsection{Objetivos}

Desenvolver a utilização do modelo Black-Literman para uma carteira de ativos de renda-fixa; e, por fim, montar uma carteira de títulos do Tesouro Nacional, utilizando recursos que aliem métodos 
quantitativos e intuição a respeito deste mercado são os principais objetivos deste trabalho.

\subsection{Contribuições}

As principais contribuições deste trabalho são as seguintes:

- 1. Realizar aplicação de séries temporais para estimar o risco de títulos emitidos pelo Tesouro Nacional.

- 2. Desenvolver a utilização do modelo Black-Literman para uma carteira de ativos de rendafixa, apresentando seus principais aspectos assim como sua utilização.

- 3. Utilizar o modelo B-L com parâmetros estimados por modelos de séries temporais.

- 4. Montar uma carteira de títulos do Tesouro Nacional, utilizando recursos que aliem métodos quantitativos e intuição a respeito deste mercado.

- 5. Apresentar a investidores e gestores de dívida uma aplicação que envolva ferramentas estatísticas e títulos de seu interesse, ou similares.

\subsection{Organização do Trabalho}

No Capítulo 2, trataremos do modelo Black-Litterman em três etapas. Começamos fazendo considerações a respeito do modelo de Markowitz e chegamos ao modelo Black-Litterman, passando pelas motivações que nos levaram a utilizá-lo e, por fim, apresentaremos a estrutura do modelo.

No Capítulo 3, tratamos de pontos fundamentais relacionados a títulos de renda fixa e, em particular, dos títulos do Tesouro Nacional, que escolhemos para trabalhar.

No Capítulo 4, tratamos dos conceitos do modelo GARCH Ortogonal e descrevemos todo o processo de estimação.

No Capítulo 5, apresentamos, em primeiro lugar, a análise de componentes principais (Sessão 5.1.1), e em seguida, a estimação do modelo GARCH (Sessão 5.1.2). Na Sessão 5.2 realizamos duas aplicações do modelo B-L. A primeira utiliza visões subjetivas do investidor. A segunda utiliza visões geradas por modelos de séries temporais. Na Sessão 5.2.3 fazemos uma comparação da performance das carterias geradas por este último modelo com a carteira de mercado.

No Capítulo 6, faremos considerações acerca das ferramentas utlizadas, seus pontos positivos e negativos, assim como, considerações a respeito dos ativos utilizados. 


\section{Capítulo 2}

\section{Modelo Black-Litterman}

\subsection{Motivação: O Modelo Markowitz de Média-Variância}

O modelo de Markowitz (1952) trata dos objetivos mais fundamentais de um investimento: maximizar o retorno esperado, minimizando risco. Talvez por esta razão, constitui a base da teoria de carteiras há mais de meio século, desde a publicação do artigo Portfolio Selection em 1952 [Mar52]. Entretanto, apesar do papel de destaque da abordagem média-variância para o meio acadêmico, várias dificuldades aparecem quando se tenta utilizá-lo na prática, e, de fato, seu impacto no mundo dos investimentos tem sido bastante limitado.

Richard Michaud(1989) [Mic89] analisa prós ${ }^{1}$ e contras, com foco nas limitações do modelo de média-variância de Markowitz. No artigo mostrou que o modelo maximiza os erros de estimação dos parâmetros na medida em que se obtêm médias amostrais a partir de dados históricos e se substitui o valor esperado pela média amostral. Michaud afirma que este procedimento não é recomendável na maioria dos casos e que isto contribui em grande maneira para a maximização dos erros. Observa que, intuitivamente, médias amostrais são sub-ótimas porque ignoram a natureza intrinsecamente multivariada do problema e que estatísticas mais poderosas são necessárias. Outra questão abordada por Michaud é a instabilidade do modelo de média-variância, de forma que pequenas alterações nos dados de entrada podem causar alterações significativas na composição da carteira. De acordo com Michaud, isto pode ser dever principalmente à matriz de covariâncias condicionadas erroneamente, usualmente relacionada a insuficientes dados históricos. De fato, o problema empírico mais alarmante ao usar o modelo de Markowtiz sem condições limitadoras é que a otimização quase sempre recomenda carteiras com enormes pesos negativos em diversos ativos, conforme também tratado por Black and Litterman em sua publicação de 1992. Gestores de carteiras, fundos e investidores, em geral, muitas vezes não têm permissão para tomar posições vendidas. Michaud menciona ainda os seguintes temas: não unicidade do equilíbrio, níveis de informação incompatíveis, otimização exata versus aproximada, inadequada potência de aproximações e definição padrão de parâmetros.

Apesar das desvantagens na utilização do modelo de média-variância de Markowitz, a ideia de maximizar o retorno, para um dado nível de risco é tão atraente para investidores ${ }^{1}$, que a busca por modelos com melhor comportamento continuou. Em 1992, Fischer Black e Robert Litterman publicam o artigo Portfolio Optimization [Bla92] fazendo considerações sobre o papel de pouco destaque da alocação quantitativa de ativos, e lançam o modelo conhecido por Black-Litterman, que se propõe a diminuir os problemas enfrentados na aplicação da teoria moderna de carteiras e, em particular, os decorrentes da aplicação do modelo de Markowitz. Posteriormente, Drobetz [Dro01], em seu artigo How to Avoid the Pitfalls in Portfolio Optimization? Putting the Black-Litterman Approach at Work.(2001) [Dro01], aborda as dificuldades em um modelo do tipo média-variância de Markowitz, e como o modelo de Black-Litterman traz avanços à teoria moderna de portifólios.

\footnotetext{
${ }^{1}$ Ver vantagens do modelo média-variância em [Mic89], página 32 : Benefits of $\boldsymbol{M} \boldsymbol{V}$ Optmizers
} 


\subsection{O Modelo}

\subsubsection{Introdução}

O modelo Black-Litterman foi publicado por Fisher Black e Robert Litterman no Journal of Fixed Income em 1991 . Posteriormente, um texto mais completo foi publicado no Financial Analysts Journal (1992) [Bla92].

Uma grande diferença entre o modelo Black-Litterman e um modelo média-variância tradicional é que enquanto o segundo gera pesos em uma carteira a partir de um processo de otimização, o modelo B-L parte de uma carteira de mercado em equilíbrio de longo prazo (CAPM). ${ }^{2}$ Enquanto o modelo MV, por conta da complexa relação entre retornos esperados e pesos da carteira resultante, gera na maioria das vezes carteiras cuja composição não parece fazer sentido, o modelo B-L fornece um ponto de partida neutro e intuitivo, na medida em que este equilíbrio de longo prazo pode ser considerado o comportamento de um investidor que representa o mercado como um todo. Black e Litterman argumentam que retornos neutros significam os retornos esperados que levariam a demandar todos os títulos em mercado, caso todos os investidores tivessem a mesma visão. Este ponto de partida fornece uma informação a priori, que se origina em um equilíbrio de longo prazo.

Ao mesmo tempo que se pode acessar um equilíbrio de longo prazo, é natural que este equilíbrio esteja sujeito a se desfazer a todo instante, no sentido das hipóteses de eficiência de mercado fraca e semi-forte. Os investidores e gestores podem ter suas próprias visões sobre o curto prazo, e, portanto, podem desejar se afastar do equilíbrio de mercado. É neste ponto que o modelo B-L traz sua segunda grande contribuição: ele fornece uma maneira clara para que investidores expressem suas visões de curto prazo e, mais importante, uma estrutura para combinar de forma consistente a informação do equilíbrio de longo prazo (priori) com a visão do investidor (curto prazo), gerando um conjunto de retornos esperados ( que é o resultado desta combinação (posteriori)), a partir do qual os pesos dos ativos são fornecidos.

\subsubsection{Estrutura}

Os retornos esperados a partir do equilíbrio de longo prazo (CAPM), podem ser obtidos por otimização reversa.

Considere a maximização da função de utilidade que contrapõe retorno e variância, conforme em: 3

$$
\begin{aligned}
\operatorname{Máx}_{\omega} & \left\{\omega^{\prime} \Pi-\frac{\delta \omega^{\prime} \Sigma \omega}{2}\right\} \quad \text { cuja solução é dada por: } \\
\omega^{*} & =(\delta \Sigma)^{-1} \Pi \quad \text { a partir da qual pode-se obter diretamente: } \\
\Pi & =\delta \Sigma \omega
\end{aligned}
$$

Sendo:

$\omega$ : Composição da carteira de mercado. $\delta$ : Coeficiente de aversão a risco

$\Sigma$ : Matriz de covariâncias estimada

$\Pi$ : Retornos implícitos no equilíbrio de mercado

O resultado em (2.3) corresponde àquele obtido pelo método conhecido por "otimização reversa". $\Pi$ em (2.3) traz os retornos esperados implícitos no equilíbrio de mercado, que servirão como ponto

\footnotetext{
${ }^{2}$ Sobre este conceito idealizado de equilíbrio de longo prazo, ver Modern Investment Management - An Equilibrium Approach [Bob03]

${ }^{3}$ A notação adotada neste trabalho busca seguir o padrão dos textos sobre o tema.
} 
de partida neutro para incorporar as visões do investidor a respeito de retornos futuros. Conforme observado por Wolfgan Drobetz [Dro01]: "Intuitivamente este procedimento está proximamente ligado ao Capital Asset Pricing Model (CAPM). Este modelo prediz que preços vão se ajustar até que, em equilíbrio de mercado, os retornos esperados serão tais que a demanda por estes ativos seja exatamente a oferta disponivel".

Inicialmente, assume-se que os retornos dos ativos são distribuidos segundo uma distribuição normal, com média esperada $\mu$ e variância conhecida $\Sigma$. Porém, $\mu$ também é uma variável aleatória, e, segundo a informação que temos a priori, é centrada em $\Pi$,

$$
\begin{aligned}
r & \sim N(\mu, \Sigma) \\
\mu & =\Pi+\epsilon^{(e)}, \\
\text { sendo que por hipótese: } \epsilon^{(e)} & \sim N\left(0, \Sigma_{\Pi}\right)
\end{aligned}
$$

Conforme apontado por Jay Walters(2009) [Wa109], uma concepção errônea comum do modelo Black-Litterman é tomar (2.4) como o modelo de referência, considerando que $\mu$ não é aleatória.

Para definir $\Sigma_{\Pi}$, Black e Litterman assumem a hipótese simplificadora de que a estrutura da matriz de covariância de $\mu$ é proporcional à covariância dos retornos $\Sigma$. Para tanto, criaram um parâmetro $\tau$, como constante de proporcionalidade. Com esta hipótese, tem-se que:

$$
\Sigma_{\Pi}=\tau \Sigma
$$

Com isto, obtemos todos os parâmetros para estimar a média da distribuição dos retornos, chamada no modelo B-L de distribuição a priori.

Em seguida, define-se a visão de curto prazo do investidor, que é expressa na forma de uma distribuição normal com média $q$ e um desvio-padrão dado por $w$. Considerando $k$ o número total de visões, seja $P$ uma matriz $k x k$ cujas colunas contêm os pesos que montam cada uma das carteiras(visões). Seja $Q$ um vetor de tamanho $k$ representando os retornos esperados em cada carteira(visão). Assim, a visão do investidor pode ser expressa conforme:

$$
P \mu=Q+\epsilon^{(v)}
$$

em que $\epsilon^{(v)}$ é uma variável não observável com distribuição normal com média zero e matriz de covariâncias $\Omega$. Supõe-se que $\epsilon^{(e)}$ de $(2.6)$ e $\epsilon^{(v)}$ de (2.8) são independentes. Usualmente também supõe-se que $\Omega$ seja uma matriz diagonal, ou seja, que as visões não são correlacionadas. He e Litterman [Bla99] argumentam que esta hipótese não é estritamente necessária. ${ }^{4}$. Ainda sobre esta hipóteses, Jay Walters [Wal09] menciona que estimar a relação entre as visões pode ser complicado e que há a tendência de se incorporar erros. Outra observação do mesmo autor sobre o tema é que não há problema que as visões sejam conflitantes, pois o processo de combiná-las irá levar em consideração o nível de confiança nas visões, assim como o nível de confiança na informação a priori.

Na restrita literatura sobre o tema, a combinação das informações a priori e visão do investidor são feitas majoritariamente sob a perspectiva da teoria bayesiana. Entretanto, a idéia de tratar o problema sob uma perspectiva frequentista (estatística clássica) também foi sugerida por Black e Litterman (1992) [Bla92], no trecho: "Uma maneira de pensar em representar a informação é agir como se tivéssemos estatísticas obtidas a partir de uma amostra dos dados obtidas da distribuição dos retornos futuros". Charlotta Mankert(2006) [Man06] apresenta o modelo sob esta perspectiva

${ }^{4}$ Ver Apêndice B 
de uma maneira bastante completa e intuitiva.

Sob a ótica da teoria Bayesiana, o modelo é assim construído, a partir do Teorema de Bayes:

$$
P(A \mid B)=\frac{P(B \mid A) P(A)}{P(B)}
$$

Considera-se:

- $P(A)$ a distribuição a priori, que corresponde às hipóteses construídas sobre a distribuição da média dos retornos, conforme em (2.4), (2.5), e (2.6). Assim, tem-se que:

$$
P(A) \sim N(\Pi, \tau \Sigma)
$$

Vale ressaltar neste ponto que a distribuição a priori está ligada à incerteza em se estimar as médias dos retornos e não a variância dos retornos propriamente dita. ${ }^{5}$ Se conhecessemos com exatidão a distribuição dos retornos, ainda sim, eles apresentariam sua própria variância. Variância esta, que não está contemplada diretamente na informação $P(A)$. A variância dos retornos, propriamente dita, será introduzida posteriormente.

- $P(B \mid A)$ a visão do investidor, dada a informação obtida do equilíbrio de longo prazo CAPM:

$$
P(B \mid A) \sim N(Q, \Omega)
$$

É justo dizer que há uma boa quantidade de hipóteses obtidas no campo das finanças para a construção desta definição. ${ }^{6}$ Satchell e Scowcroft em A demystification of the Black-Litterman model [Ste00] contribuem para o entendimento das hipóteses por trás desta definição. Na prática, quer dizer que os retornos de equilíbrio condicional às escolhas individuais são iguais à visão do investidor, em média. Esta idéia é intimamente ligada àquela mencionada anteriormente sobre o equilíbrio de longo prazo. Intuitivamente, pode-se pensar na relação das escolhas individuais e no resultado agregado do mercado em um universo de investimentos do tipo CAPM.

- $P(B)$ é a distribuição marginal da visão do investidor e esta não será modelada, pois no modelo desaparecerá como constante de integração.

Aplicando o teorema de Bayes, chega-se à distribuição a posteriori: ${ }^{7}$

$$
P(A \mid B) \sim N\left(\left[(\tau \Sigma)^{-1}+P^{T} \Omega^{-1} P\right]^{-1}\left[(\tau \Sigma)^{-1} \Pi+P^{T} \Omega^{-1} Q\right],\left[(\tau \Sigma)^{-1}+P^{T} \Omega^{-1} P\right]^{-1}\right) .
$$

Uma vez encontrada a variância da distribuição resultante, cabe-nos voltar ao ponto em que

\footnotetext{
${ }^{5}$ Isto está mencionado em He and Litterman [Bla99]

${ }^{6}$ Ver Hiemstra (1997): For a construction of CAPM model based on heterogeneous expectations by investors

${ }^{7}$ Ver Apêndice A. A demonstração seguiu os passos indicados em Satchell and Scowcroft(2000) [Ste00]
} 
mencionamos o fato de que as hipóteses de $P(A)$ não incluiam a variância dos retornos. Assim, para a variância total da posteriori, há que se somar a variância dos retornos:

$$
\Sigma_{p}=\Sigma+\left[(\tau \Sigma)^{-1}+P^{T} \Omega^{-1} P\right]^{-1} .
$$

Esta é a variância a posteriori do chamado modelo referência de Black-Litterman. Vários autores desconsideram as considerações sobre $P(A)$ (na página anterior), montando o que se chamou de modelo alternativo. 


\section{Capítulo 3}

\section{Carteira de Títulos do Tesouro Nacional}

\subsection{Motivação}

Tanto a escolha do modelo B-L, quanto a escolha por utilizar uma carteira de títulos emitidos pelo Tesouro Nacional tiveram como motivação o objetivo de aproximar ferramentas estatísticas de aplicações em finanças, em particular, títulos públicos federais emitidos em mercado, que têm se tornado cada vez mais conhecidos pelos investidores pessoas físicas, sobretudo através do programa Tesouro Direto. Ao fazê-lo, espera-se que este estudo traga informações úteis tanto para investidores, quanto para gestores de dívida, uma vez que o modelo média-variância presta-se tanto para aqueles que adquirem títulos, buscando, portanto, maximizar retorno para um dado nível de risco, quanto para aqueles que emitem títulos, e que, portanto, buscam reduzir seus custos de emissão a níveis prudenciais de risco. De fato, muitos emissores de dívida buscam encontrar uma carteira ótima em termos de risco e custo. É o caso da Itália, Suiça, Brasil, dentre outros. Para conhecer a experiência brasileira de na busca de uma carteira ótima na gestão de dívida, ver Alves(2009) [Alv09]. Se este trabalho puder trazer contribuições a estes ou a qualquer outro emissor que venha a estudar o assunto, este trabalho terá atingido plenamente seus objetivos.

\subsection{Metodologia}

Conforme mencionado anteriormente, nesta aplicação optou-se por montar uma carteira de títulos de renda fixa, mais especificamente, de títulos emitidos pelo Tesouro Nacional no mercado brasileiro. A inclusão de títulos emitidos no exterior também seria uma opção, porém, estes, além de apresentarem no passado recente um diferencial de taxas (para menor) bastante considerável, apresentam pouca liquidez e, portanto, certa ineficiência em termos de precificação diária. Em conclusão, para o propósito de montar uma carteira ótima em termos de retorno e risco, não agregaria ao trabalho - sem prejuízo de que estas considerações deixem de ser verdadeiras em um futuro próximo, e que eles possam vir a ser considerados.

Atualmente, no chamado mercado doméstico, o Tesouro realiza emissão de títulos prefixados, com e sem cupom, pós-fixados vinculados à taxa referencial SELIC, pós-fixados vinculados ao índice de inflação IPCA. Por sua característica de repactuação diária, a remuneração dos pós-fixados vinculados à SELIC poderia cumprir a função de taxa livre de risco. Entretanto, por peculiaridades do mercado nacional, estes títulos oferecem remuneração desproporcional ao risco e ao prazo (um dia) dos mesmos, fazendo com que este título seja sempre preferível em termos de risco x retorno, quando comparados com os demais. Por conta disso, serão excluídos do roll de títulos a serem estudados. Na prática, de fato há uma preferência por tais títulos, e, quando o mercado adquire papéis de outra natureza, o que se faz é uma proteção (hedge) no mercado de derivativos, contra o risco dos pré-fixados, de tal sorte que uma grande parcela do mercado local esteja sempre ativa em taxas pós-fixadas, de baixo risco portanto. Exceção pode ser feita, em alguns casos, para investidores estrangeiros, investidores institucionais e algumas estruturas de hedge funds. Em suma, 
consideraremos os títulos: LTN (prefixados sem cupom), NTN-F(prefixados com cupom) e NTN$\mathrm{B}$ (vinculados a índice de preço IPCA), em suas diversas maturações, que vão de alguns poucos meses a aproximadamente 30 anos.

Neste ponto cabe ressaltar que, por força de tais características de nosso mercado, e porque buscamos montar uma carteira sujeita a risco de taxas, nossa carteira de equilíbrio de longo prazo (CAPM) não será dada pela carteira em mercado propriamente dita, e sim, pela carteira do segmento de investidores que se expõem ao risco da variação de taxas em nosso mercado local, ou seja, principalmente investidores estrangeiros. Para a obtenção desta carteira (composição e prazos) analisamos os dados publicados no Relatório Anual da Dívida Pública Federal de 2010 e fizemos aproximações e assumimos hipóteses simplificadoras. A composição obtida segue abaixo:

\begin{tabular}{|c|c|c|c|c|c|c|c|c|c|}
\hline Pré $_{1 A}$ & $\mathrm{IPCA}_{2 A}$ & Pré $_{2 A}$ & IPCA $_{3 A}$ & Préé $_{3 A}$ & $\mathrm{IPCA}_{5 A}$ & Prée $_{5 A}$ & IPCA $_{10 A}$ & IPCA $_{20 A}$ & IPCA $_{30 A}$ \\
\hline $36 \%$ & $5 \%$ & $20 \%$ & $5 \%$ & $3 \%$ & $4 \%$ & $23 \%$ & $2 \%$ & $1 \%$ & $1 \%$ \\
\hline
\end{tabular}

Tabela 3.1: Composição da carteira de mercado.

Uma vez que nossa análise se estende por perído relativamente longo, enfrentamos a dificuldade de utilizar os títulos diretamente, pois à medida que o tempo passa, seus prazos para vencimento (maturações) se reduzem, alterando as características dos mesmos. Diferentemente de um título perpétuo ou ação, que não possuem prazo de vencimento, os títulos em estudo são emitidos com vencimento pré definido. Assim, mais do que utilizar títulos, precisamos de benchmarks que representem tanto determinado tipo de remuneração, quanto determinada maturação, de forma consistente ao longo do tempo.

Por conta de tais dificuldades, o mercado já sentia a necessidade de construir índices de referência (benchmarks) que cumpram a função de representar títulos (ou a remuneração dos títulos) em prazos definidos e constantes. Para atender esta necessidade, a Anbima (Associação Brasileira das Entidades dos Mercados Financeiros e de Capitais) criou os índices de duração constante (IDkA), que passaram a ser publicados em 2009, com série histórica iniciando-se em 2006. Os índices são calculados em vértices da estrutura a termo da taxa de juros (ETTJ) publicada pela Anbima, construídas com base no mercado secundário de títulos emitidos pelo Tesouro Nacional. No segmento de prefixados, são divulgados índices com duração de 3 meses, 1, 2, 3 e 5 anos. Para os indexados ao IPCA, as durações disponíveis são: 2, 3, 5, 10, 20 e 30 anos. Para mais detalhes sobre a composição e construção do índice, ver Índice de Duração Constante Ambima - Metodologia [Anb]. Vale ressaltar que o índice prefixado de 3 meses não será incluído em nossa base de dados, pois sua negociação no mercado secundário reflete, de certa forma, a baixa incerteza e a baixa diversidade de visões até o seu vencimento em função da proximidade de sua data de maturação, de forma que sua rentabilidade diária acaba refletindo a média das taxas de emissão daqueles títulos, e, portanto, não apresenta variações de preço oriundas de assunção de risco significativas a ponto de valer a pena incluí-lo em nosso estudo. Assim, trabalharemos com 10 séries temporais.

\subsection{Séries Temporais}

Nossas séries de retornos diários se estendem de janeiro de 2006 a julho de 2011. Entretanto, para a finalidade de montar uma carteira e rebalanceá-la, a frequência diária não faria sentido, pois seria impraticável fazê-lo, seja por questões de mercado, operacionais e de custos. Assim, optamos por tranformar nossos retornos diários em semanais. Outro fator igualmente importante a respeito da frequência dos dados é aquele observado no Capítulo 4.4, a respeito do fato estilizado sobre caudas pesadas. 


\begin{tabular}{|c|c|c|c|c|c|c|c|c|c|}
\hline Pré1A & IPCA2A & Pré2A & IPCA3A & Pré3A & IPCA5A & Pré5A & IPCA10A & IPCA20A & IPCA30A \\
\hline 7.35 & 6.77 & 7.75 & 6.99 & 8.28 & 7.67 & 8.60 & 7.79 & 7.31 & 6.49 \\
\hline
\end{tabular}

Tabela 3.2: Curtose das séries.

\begin{tabular}{|c|c|c|c|c|c|c|c|c|c|}
\hline Pré1A & IPCA2A & Pré2A & IPCA3A & Pré3A & IPCA5A & Pré5A & IPCA10A & IPCA20A & IPCA30A \\
\hline 0.72 & 0.26 & 0.24 & -0.20 & -0.04 & -0.89 & -0.28 & -0.61 & -0.38 & -0.30 \\
\hline
\end{tabular}

Tabela 3.3: Assimetria das séries.

Assim, inicialmente fizemos a agregação, transformando os retornos de todas as semanas em taxa expressa em período de 5 dias, com a equação (3.1), para que todas sejam expressas em períodos de igual duração. Sendo $P_{f(t, i)}$ o número índice da série $i$ ao fim da semana $t$ e $P_{f(t-1, i)}$ o número índice ao fim da semana anterior, calcula-se o retorno expresso em taxa expressa em período semanal. Posteriormente, calculam-se os log-retornos com a equação ( 3.2$){ }^{1}$

$$
\begin{aligned}
r_{\text {semanal }_{(t, i)}} & =\left(\frac{P_{f(t, i)}}{P_{f(t-1, i)}}\right)^{\left(5 / \text { diasnasemana }_{t}\right)}-1, \\
\operatorname{logr}_{\text {semanal }(t, i)} & =\log \left(1+r_{\text {semanal } \left._{(t, i)}\right)}\right)
\end{aligned}
$$

Procedendo desta forma obtivemos 278 observações em cada uma das 10 séries temporais. Quatro séries do segmento de prefixados nas durações de 1, 2, 3 e 5 anos; seis séries de índices indexados ao IPCA, com maturações de 2, 3, 5, 10, 20 e 30 anos, conforme Figura 3.1. Destacamos que apesar de termos obtido 278 observações, utilizaremos 274 para a estimação do modelo, e guardaremos as 4 últimas para verificar o resultado das previsões realizadas na Sessão 5.2.2.

Na Figura 3.2 apresentamos os histogramas que, juntamente com a função densidade de probabilidade normal, evidenciam a presença de caudas pesadas nas distribuições. Além disso, ao fazer o gráfico QxQ plot das séries versus distribuição normal, fica ainda mais evidenciada a presença de retornos na extremidade da distribuição. Além disso, ao executar o teste de Bera e Jarque ${ }^{2}$, temos a confirmação de que as distribuições não são normais.

De fato, ao calcular a curtose, vemos claramente na Figura 3.3 a presença de caudas pesadas. Vale observar que os dados diários apresentam curtose bastante superior. Estes valores foram reduzidos ao adotarmos a frequência semanal, conforme observação no Capítulo 4.4 a respeito do fato estilizado caudas pesadas. Segue também na Tabela 3.3 a assimetria das séries, que mostram valores não desprezíveis.

Por último, nesta sessão, apresentamos o gráfico dos retornos acumulados na Figura 3.4, ou, de forma equivalente, do número índice de cada uma das 10 séries sob análise. Conhecer o comportamento do retorno acumulado será particularmente útil para a análise dos resultados finais do modelo. De pronto, vemos que algumas séries se destacam. O IPCA de 30 anos apresenta o maior retorno acumulado, ao mesmo tempo que também apresenta a maior volatilidade de todas. O índice IPCA de 20 anos vem logo abaixo em termos dessas duas grandezas. Com menores diferenças, porém com uma igualmente alta correlação vêm os demais vértices da curva, nos papéis prefixados e vinculados a índice de preços. O desafio deste trabalho é verificar se o modelo é capaz de dar uma

\footnotetext{
${ }^{1}$ Para retornos de séries financeiras, ver Morettin (2011), pg 6 [Mor11]

${ }^{2}$ Para teste de normalidade, ver Morettin (2011), pg 24 [Mor11]
} 

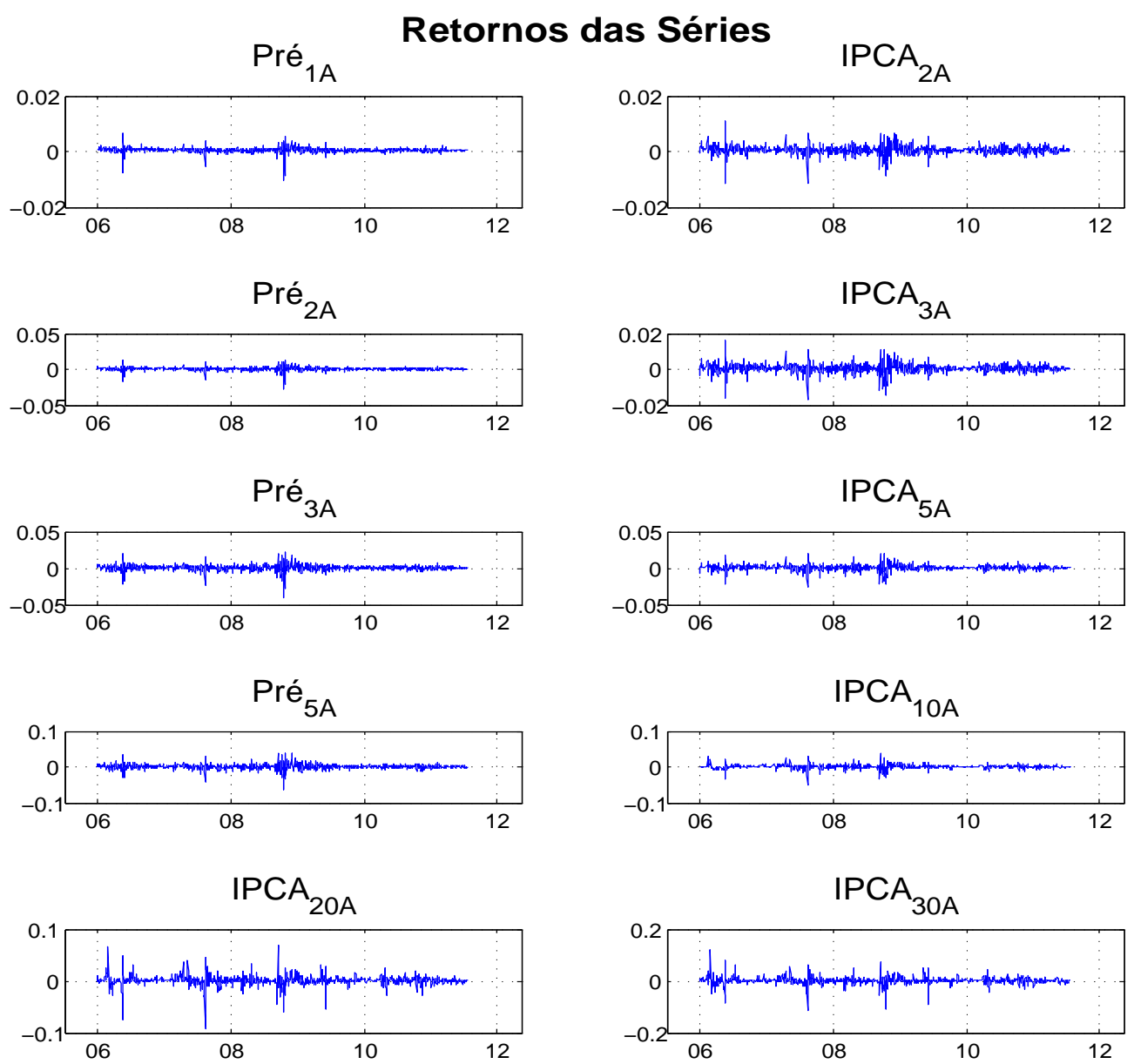

Figura 3.1: Retornos das séries.

resposta satisfatória otimizando a relação retorno x risco e conseguir encontrar a melhor composição de carteira em cada momento. Para tanto, em primeiro lugar, dependeremos de o modelo GARCH ser capaz de estimar adequadamente as covariâncias e sua evolução à luz dos fatos estilizados citados anteriormente. Em segundo, uma boa resposta também dependerá de o modelo B-L conseguir estimar a carteira que maximize os objetivos do investidor. 


\section{Histogramas das Séries}
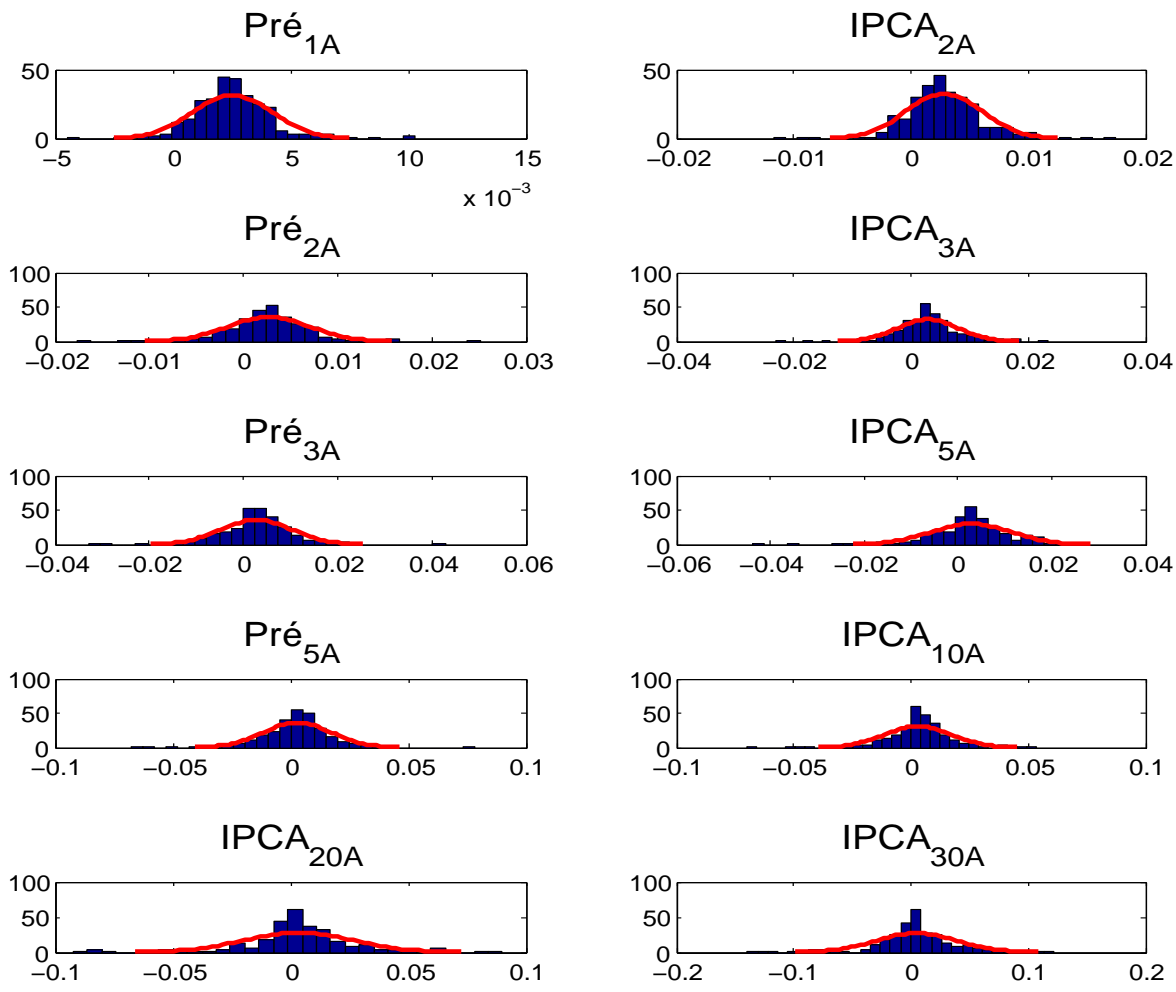

Figura 3.2: Histogramas com normal ajustada. 


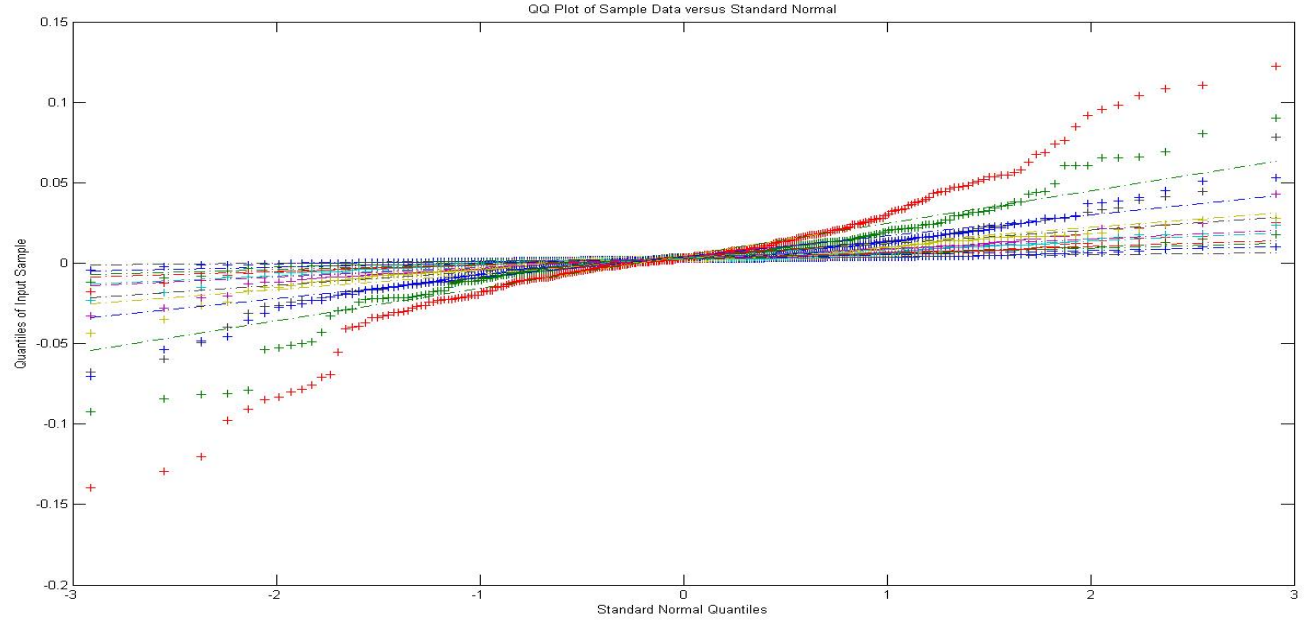

Figura 3.3: $Q \times Q$ plot. 


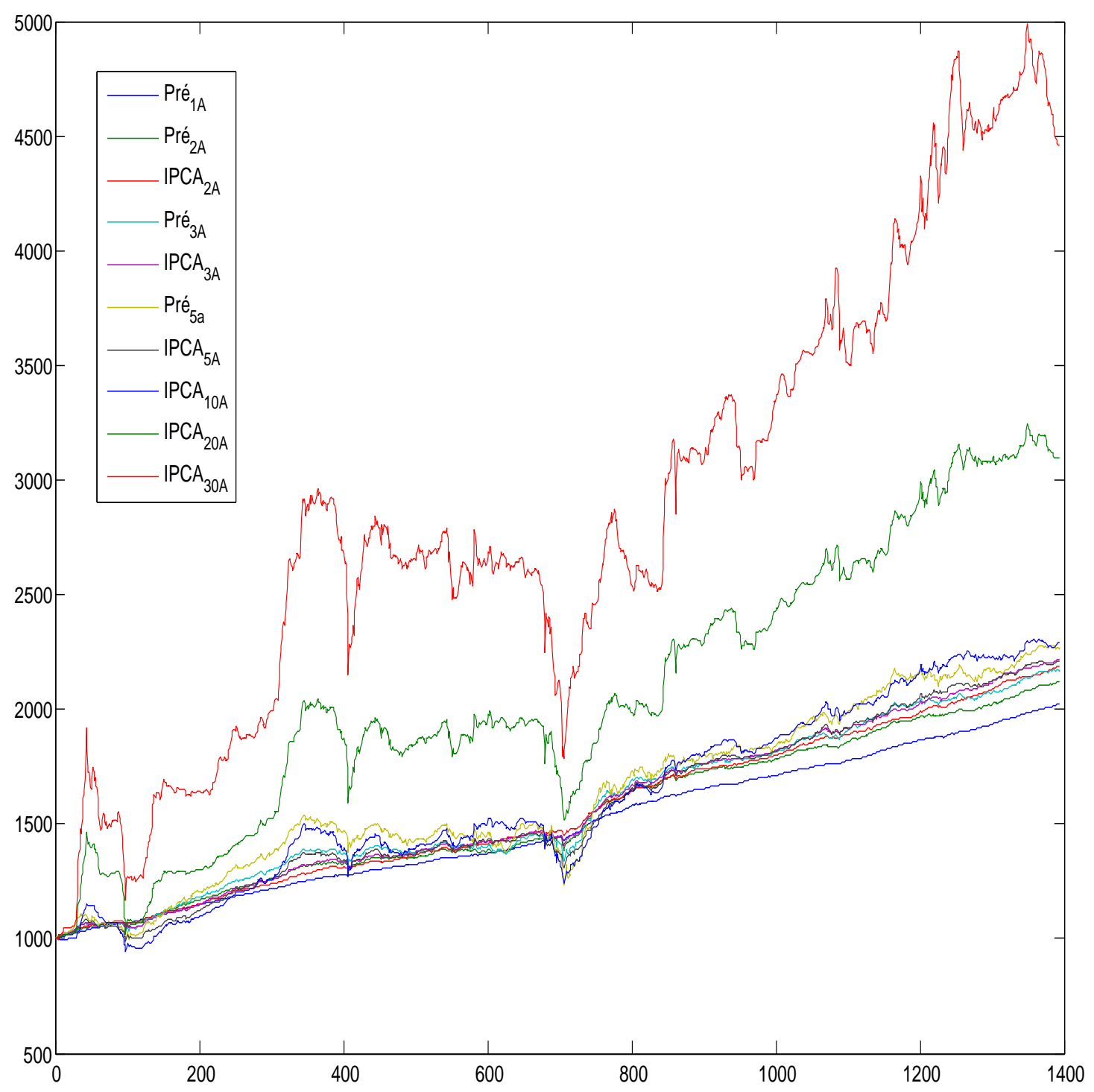

Figura 3.4: Números indices das séries. 


\section{Capítulo 4}

\section{Modelo GARCH Ortogonal}

\subsection{Introdução}

Porque o risco de uma carteira é fundamentalmente determinado pela matriz de covariâncias de seus ativos, matrizes de grande dimensão têm um papel importante na avaliação de investimentos. No centro de quase todos os modelos de risco, há uma matriz de covariâncias que captura variâncias e covariâncias entre fatores de risco. A obtenção de matrizes não negativas definidas representa um grande desafio para analistas, pois o seu cálculo é complexo e, frequentemente, medidas muito simples são utilizadas nesta matriz de covariâncias. Por exemplo, o método Riskmetrics desenvolvido pelo JP Morgan utiliza médias móveis ponderadas exponencialmente, com a mesma constante de suavização para todos os retornos.

Os modelos GARCH multivariados, por sua vez, têm sido objeto de extensa pesquisa, entretanto, a implementação destes ainda é bastante complexa. Uma, de várias boas razões para a continuidade dos estudos, decorre de o modelo GARCH normalmente levar a estruturas a termo de volatilidade e correlações reversíveis à média, com uma forma analítica simples. Tem havido extensa pesquisa sobre diferentes maneiras de se parametrizar o GARCH multivariado, de forma que a matriz de covariâncias seja positiva definida - ver Engle e Mezrich (1996). Entretanto, à medida em que a dimensão se amplia, chega-se a um ponto em que o GARCH multivariado não pode ser utilizado para estimar diretamente grandes matrizes de covariâncias, que são necessárias para avaliar o risco de uma grande carteira. Com tantos parâmetros, a função de verossimilhança se torna muito plana, fazendo com que problemas de convergência numérica sejam comuns nas rotinas de otimização.

Assim, a escolha do método GARCH ortogonal se deve ao fato de que este pode gerar matrizes de covariâncias do modelo original a partir de algumas poucas volatilidades univariadas, sendo, portanto, um método computacionalmente bastante simples. De fato, sendo $k$ o número de váriáveis, as $k(k+1) / 2$ variâncias e covariâncias são transformações de duas ou três variâncias obtidas pela estimação GARCH. O modelo é uma generalização do modelo GARCH de um fator introduzido por Engle, Ng e Rothschild (1990) [Eng01] para um modelo multifatorial com fatores ortogonais.

Neste trabalho os fatores ortogonais são obtidos por meio de componentes principais. A idéia de utilizá-las em um modelo GARCH multivariado iniciou-se com Ding(1994), em sua tese de doutorado. Ding utilizou o número total de componentes e seus resultados não foram satisfatórios. A idéia de utilizar um espaço reduzido de componentes principais foi apresentado por Alexander e Chibumba (1996), e posteriormente desenvolvido por Alexander (2000) e Klaassens (2000). Engle (2000) mostra que o GARCH ortogonal tem resultados bons. Neste modelo de dimensão reduzida, suficientes fatores de risco serão considerados, assim, os demais movimentos, ou seja, aqueles não capturados por estes fatores, serão considerados ruídos insignificantes para este sistema. Expurgar o que se pode considerar ruído torna as medidas de risco mais robustas ao longo do tempo e permite a utilização do modelo em mercados pouco líquidos e em novas emissões, ou seja, situações em que 
existe considerável presença de ruído, conforme considerado por Wilmott em Carol Alexander's The Exorcist [Wil01]. Em outras palavras, controlar o número de componentes principais para capturar apenas as variações mais relevantes, ao invés de incluir variações pequenas de movimentos insignificantes ou "ruído", faz com que as estimativas das correlações sejam mais estáveis do que aquelas estimadas diretamente.

Ao mesmo tempo, quantificar a variabilidade que cada fator de risco é de grande relevância, pois o gestor de risco poderá direcionar mais facilmente sua atenção para os fatores mais relevantes. A redução da dimensionalidade é outra propriedade do modelo ortogonal, que não seria possível sem restrições na parametrização direta em um GARCH multivariado.

O modelo GARCH ortogonal apresenta a vantagem de as variâncias dos ativos e as covariâncias com os outros ativos do sistema serem derivadas das variâncias das componentes principais, que são comuns a todos os ativos e dos pesos dos fatores que são específicos de cada ativo em particular.

\subsection{Estrutura}

Seja a matriz de dados $X$ com $T$ observações e $k$ variáveis. Na análise de componentes principais, primeiramente padroniza-se variável a variável, fazendo $x_{i}=\left(y_{i}-\mu_{i}\right) / \sigma_{i}$, com $i=1, \ldots, k$, em que $\mu_{i}$ e $\sigma_{i}$ são, respectivamente, a média e o desvio padrão da série $i$. Supondo $X$ com dimensão $T \times k, X^{\prime} X$ será $(k \times k)$, simétrica e com 1's na diagonal principal. Cada componente principal será combinação das colunas de $X^{\prime} X$. Seus pesos serão obtidos a partir da matriz de autovetores de $X^{\prime} X$, de tal forma que a primeira componente principal explica o máximo da variância total, a segunda explica o máximo da variância remanescente e assim por diante, sendo que as componentes são não correlacionadas.

Sejam $W$ e $\lambda$ as matrizes de autovetores e autovalores de $X^{\prime} X$, respectivamente. Assim, temos que:

$$
X^{\prime} X W=W \lambda
$$

Sendo $P$ a matriz com as componentes principais, temos:

$$
\begin{gathered}
P=X W \\
X=P W^{\prime}
\end{gathered}
$$

ou seja,

$$
X_{i}=w_{i 1} P_{1}+w_{i 2} P_{2}+. .+w_{i k} P_{k}
$$

$X$, portanto, pode ser escrita como combinação linear das componentes principais. O montante de variabilidade de $X$ que é explicado pela i-ésima componente principal é $\lambda_{i} /\left(\sum_{i=1}^{k} \lambda_{i}\right)$

Da mesma forma, as variáveis originais podem ser representadas por :

$$
Y_{i}=\mu_{i}+w_{i 1}^{*} P_{1}+w_{i 2}^{*} P_{2}+. .+w_{i u}^{*} P_{u}+\epsilon_{i},
$$


Sendo que $\epsilon_{i}$ representa o erro da aproximação por utilizar um número de componentes principais menor do que o número de variáveis $(u \leq k)$ e $w_{i j}^{*}=w_{i j} \sigma_{i}$.

Tomando a variância de (4.5) obtem-se:

$$
V=A D A^{\prime}+V_{\epsilon},
$$

sendo $A$ a matriz dos pesos dos fatores $\left(w_{i j}^{*}\right), D$ uma matriz diagonal contendo as variâncias das componentes principais e $V_{\epsilon}$ a matriz de covariâncias dos erros por estarmos utilizando um número de componentes $u$, inferior ao número total de variáveis. Com isso, o modelo permite gerar matrizes de covariâncias a partir da estimação univariada da variância de algumas componentes principais.

No modelo GARCH ortogonal, a estimação da série temporal de variâncias é feita por um modelo GARCH. Uma vez obtidas as séries, pode-se gerar matrizes de covariâncias a partir de (4.6), para cada instante no tempo, obtendo:

$$
V_{t}=A D_{t} A^{\prime}
$$

A precisão ao se desconsiderar $V_{\epsilon}$ irá depender de o número de componentes principais ser suficiente para explicar grande parte da variação do sistema. Logo, o método funcionará melhor quando a análise de componentes principais funcionar melhor, isto é, em estruturas a termo e outros sistemas altamente correlacionados. Em um sistema com alta correlação, apenas algumas poucas componentes são necessárias para representar toda a variação do sistema com um alto grau de precisão - o que é bem melhor do que calcular $k(k+1) / 2$ variâncias e correlações diretamente.

Outra observação importante é que as componentes principais são apenas incondicionalmente não correlacionadas, portanto, a matriz de covariâncias GARCH não é necessariamente diagonal, mas esta hipótese tem que ser assumida, caso contrário, perde-se o grande objetivo do modelo de gerar grandes matrizes de covariâncias a partir de variâncias GARCH univariadas, conforme observado por Alexander(2001) [Ale01a]

\subsection{Vários Fatores de Risco}

Neste ponto, vale ressaltar que o modelo GARCH ortogonal continua igualmente útil e viável quando pretende-se gerar matriz de covariâncias de diferentes fatores de risco, ou seja, tanto dos altamente correlacionados, quanto daqueles pouco correlacionados. Não é raro ter em uma carteira riscos diversos, tais como, taxas de câmbio, ações, commodities, renda fixa e outros. Conforme posto por Wilmott em [Wil01], basta dividir os ativos em categorias de acordo com o tipo de instrumento, região geográfica, em suma, todas as divisões razoáveis para agrupar tais ativos. Feito isto, igualmente utiliza-se componentes principais para extrair os fatores de risco chave para cada categoria, obtendo-se as matrizes de covariâncias usando GARCH, por exemplo. Posteriormente, os pesos dos fatores são utilizados para combinar todas as matrizes de covariâncias obtidas, gerando a matriz de covariâncias do sistema original.

A título de ilustração, considere um sistema com $r$ componentes principais e outro com $s$. Sejam suas componentes: $P=\left(P_{1}, . ., P_{r}\right)$ e $Q=\left(Q_{1}, . ., Q_{s}\right)$, respectivamente. Sejam ainda $A(n \times r)$ e $B(m \times s)$ as respectivas matrizes de fatores padronizados e $D_{1}$ e $D_{2}$ as respectivas matrizes dia- 
gonais das variâncias de cada um dos dois sistemas. Com isso, temos que a matriz de covariâncias em cada um dos sistemas será, respectivamente: $A D_{1} A^{\prime}, B D_{2} B^{\prime}$.

Para gerar a matriz de covariâncias do sistema total, toma-se $C=C O V\left(P_{i}, Q_{j}\right)$ para todas as componentes, obtendo:

$$
\left[\begin{array}{cc}
A D_{1} A^{\prime} & A C B^{\prime} \\
\left(A C B^{\prime}\right)^{\prime} & B D_{2} B^{\prime}
\end{array}\right]
$$

A ilustração serve para pontuar acerca do escopo e da flexibilidade do sistema ao tratar de quaisquer conjuntos de fatores de risco. Uma vez que os fatores sejam divididos em categorias com ativos com alta correlação, a análise de componentes principais será capaz de extrair fontes importantes de fatores de risco não correlacionados, para que posteriormente sejam combinados em uma única matriz de covariâncias para todos os ativos da carteira.

\subsection{Estimação GARCH}

O modelo ARCH foi proposto por Engle (1982) e sua generalização (GARCH) se deve a Bollerslev (1986). Conforme posto em Morettin(2011) [Mor11], da mesma forma que um modelo ARMA pode trazer menos parâmetros do que um modelo AR ou MA, o modelo GARCH pode representar a volatilidade com menos parâmetros. O modelo GARCH é expresso como uma função linear dos quadrados da série(retornos) e da própria variância condicional. Neste modelo a variância condicional é o conceito chave e sua especificação é capaz de capturar os principais fatos estilizados que caracterizam as séries temporais financeiras.

Entende-se por fatos estilizados padrões estatísticos observados empiricamente, que, acreditase serem comuns a um grande número de séries temporais. Séries financeiras com suficiente alta frequência (observações intraday, diárias e até semanais) costumam apresentar tais características.

Um primeiro fato estilizado digno de nota é a estacionariedade fraca ou de segunda ordem dos retornos ${ }^{1}$. Este padrão denota a livre variação da magnitude dos retornos, entretanto, com a manutenção da média muito próxima de zero. Um segundo fato estilizado é a ausência de autocorrelação dos retornos. Variações de preços usualmente mostram baixa autocorrelação, tornando-as comparáveis a um ruído branco. Um outro padrão conhecido é a presença de autocorrelação dos retornos ao quadrado, o que não invalida a hipótese de ruído branco para os retornos, porém, mostra que o ruído branco não é do tipo forte. O clustering da volatilidade é uma outra característica bastante encontrada em séries de retornos. Trata-se da presença de subperíodos de alta volatilidade e outros de baixa, ou seja, a presença de persistência de retornos de alta magnitude e, em outros momentos, a persistência de retornos de baixa magnitude. A presença de caudas pesadas na função densidade também é bastante comum, sobretudo em dados de maior frequência. À medida que o intervalo de tempo no qual os retornos são calculados aumenta, a leptocurticidade tende a desaparecer e a distribuição tende a se aproximar de uma normal. O chamado efeito de alavancagem, ou assimetria da volatilidade, foi notado por Black(1976) e denota o efeito de retornos positivos e negativos na volatilidade. Retornos negativos tendem a criar impactos na volatilidade maiores do que retornos positivos de mesma magnitude. Por último, vale ressaltar a sazonalidade, que trata do efeito de eventos de calendário que afetam as séries de retornos (feriados, safras, dias da semana, eventos climáticos, etc..).

\footnotetext{
${ }^{1}$ Para definição de processo estocástico fracamente estacionário, ver Morettin (2011), pg 30 [Mor11]
} 
Sem dúvida os fatos estilizados presentes em séries financeiras impõem um grande desafio a sua modelagem. A não predição dos retornos, a leptocurticidade e a autocorrelação dos retornos ao quadrado são de particular interesse neste tipo de série temporal em estudo.

Um modelo $\operatorname{GARCH}(\mathrm{m}, \mathrm{n})$ é definido por:

$$
\begin{aligned}
r_{t} & =\sqrt{h_{t}} \epsilon_{t} \\
h_{t} & =\alpha_{0}+\sum_{i=1}^{m} \alpha_{i} r_{t-i}^{2}+\sum_{j=1}^{n} \beta_{j} h_{t-j},
\end{aligned}
$$

em que $\epsilon_{t}$ são v.a. i.i.d., com média zero, $\alpha_{0}>0, \alpha_{i} \geq 0, i=1, \ldots, m-1, \beta_{j} \geq 0, j=1, \ldots, n-1$, $\alpha_{m}>0, \beta_{n}>0, \sum_{i=1}^{q}\left(\alpha_{i}+\beta_{i}<1\right), q=\max (m, n)$.

É possível observar no modelo que variâncias altas, assim como retornos ao quadrado altos, dão origem a valores estimados de volatilidade também altos (clustering da volatilidade). Outra avaliação que pode ser feita do modelo é que se a série segue um modelo GARCH, em sua distribuição haverá a presença de caudas pesadas. Conforme em Morettin (2011) [Mor11], a respeito da curtose, mais especificamente, a respeito da leptocurticidade, é possível mostrar que:

$$
K=\frac{E\left(r_{t}^{4}\right)}{\left[E\left(r_{t}^{2}\right)\right]^{2}}=\frac{3\left[1-\left(\alpha_{1}+\beta_{1}\right)^{2}\right]}{1-\left(\alpha_{1}+\beta_{1}\right)^{2}-2 \alpha_{1}^{2}}>3
$$

Interessante observar que o parâmetro $\alpha$ corresponde à magnitude da "reação do mercado", enquanto o parâmetro $\beta$ representa a "persistência da volatilidade". Quanto aos estimadores de tais parâmetros, estes são obtidos pela máxima verossimilhança condicional. Conforme em Morettin (2011) [Mor11], supondo normalidade dos $\epsilon_{t}$, tem-se que a log-verossimilhança condicional às primeiras m observações é dada por:

$$
l\left(r_{m+1}, \ldots, r_{T} \mid \alpha, \beta, r_{1}, \ldots . r_{m}\right) \propto-\frac{1}{2} \sum_{t=m+1}^{T} \ln \left(h_{t}\right)-\frac{1}{2} \sum_{m+1}^{T} \frac{r_{t}^{2}}{h_{t}}
$$

Com isso, observa-se que os padrões conhecidamente presentes em séries temporais financeiras estão contemplados na estrutura deste modelo original, exceção feita ao fato estilizado efeito de alavancagem, ou assimetria da volatilidade. De fato, o modelo GARCH trata de forma simétrica o efeito de retornos positivos e negativos sobre a volatilidade, quando, na verdade, sabemos que a assimetria deste impacto é o que mais se verifica. Para dar conta desta característica, Nelson (1991) introduziu os modelos EGARCH. Nestes, retornos negativos terão impacto sobre a volatilidade superior, quando comparados com o impacto de retornos positivos de mesma magnitude. 2

Assim como nos modelos ARCH, previsões de volatilidade podem ser calculadas no modelo GARCH. Consideremos um modelo $\operatorname{GARCH}(1,1)$ com origem t. Utilizando (4.9), temos:

$$
\hat{h}_{t}(1)=\alpha_{0}+\alpha_{1} r_{t}^{2}+\beta_{1} h_{t},
$$

\footnotetext{
${ }^{2}$ Ver Morettin (2011)[Mor11], pg 139, para modelos EGARCH
} 
para um $l>1$,

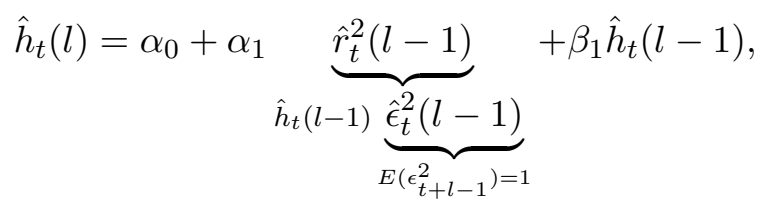

obtendo-se

$$
\hat{h}_{t}(l)=\alpha_{0}+\left(\alpha_{1}+\beta_{1}\right) \hat{h}_{t}(l-1), l>1 .
$$

Utilizando (4.12) sucessivamente, pode-se construir:

$$
\begin{aligned}
\hat{h}_{t}(l) & =\alpha_{0}+\left(\alpha_{1}+\beta_{1}\right) \hat{h}_{t}(l-1), \\
& =\alpha_{0}+\left(\alpha_{1}+\beta_{1}\right)\left[\alpha_{0}+\left(\alpha_{1}+\beta_{1}\right) \hat{h}_{t}(l-2)\right], \\
& =\alpha_{0}+\alpha_{0}\left(\alpha_{1}+\beta_{1}\right)+\left(\alpha_{1}+\beta_{1}\right)^{2} \hat{h}_{t}(l-2), \\
& =\alpha_{0}+\alpha_{0}\left(\alpha_{1}+\beta_{1}\right)+\alpha_{0}\left(\alpha_{1}+\beta_{1}\right)^{2}+\left(\alpha_{1}+\beta_{1}\right)^{3} \hat{h}_{t}(l-3), \text { para } l-1 \\
& =\alpha_{0}+\alpha_{0}\left(\alpha_{1}+\beta_{1}\right)+\ldots+\alpha_{0}\left(\alpha_{1}+\beta_{1}\right)^{l-2}+\left(\alpha_{1}+\beta_{1}\right)^{(l-1)} \hat{h}_{t}(1),
\end{aligned}
$$

Finalmente obtendo uma equação fechada para previsão em qualquer passo $l$, sem precisar conhecer explicitamente as previsões intermediárias:

$$
\hat{h}_{t}(l)=\frac{\alpha_{0}\left(1-\left(\alpha_{1}+\beta_{1}\right)^{l-1}\right)}{\left(1-\left(\alpha_{1}+\beta_{1}\right)\right)}+\left(\alpha_{1}+\beta_{1}\right)^{(l-1)} \sigma_{h}^{2}(1) .
$$




\section{Capítulo 5}

\section{Aplicação}

\subsection{Modelo GARCH Ortogonal}

\subsubsection{Componentes Principais}

Fazendo a análise de componentes principais, conforme equação 4.1, observamos, a partir dos valores ordenados dos autovalores, que com quatro componentes conseguimos explicar $96.8 \%$ da variabilidade das séries, conforme Tabela 5.1 abaixo.

\begin{tabular}{|c|c|}
\hline Autovalor & $\lambda / \Sigma \lambda$ \\
\hline 7.4920 & 0.7492 \\
1.2780 & 0.8770 \\
0.5625 & 0.9332 \\
0.3473 & 0.9680 \\
\hline
\end{tabular}

Tabela 5.1: Variância explicada pelas componentes.

A Tabela 5.2 mostra os pesos de cada um dos fatores. A primeira componente apresenta pesos muito parecidos para todas as séries. Pesos parecidos e altos mostram a alta correlação deste sistema. A primeira e a última séries são as que apresentam menor correlação com o resto do sistema. Um deslocamento positivo da componente 1 causará um deslocamento paralelo na curva de retornos, ao longo de todos os índices. Por esta razão, a componente 1 é chamada de componente de tendência da curva. Esta componente de tendência explica aproximadamente $75 \%$ da variação do sistema. Para analisar a segunda componente, observemos os prazos e os índices separadamente. Se olharmos os prefixados, vemos que seus fatores são monotonicamente crescentes, assumindo valores negativos e positivos. Com exceção do IPCA $20 A$, os fatores dos índices de preços também são monotonicamente crescentes. Um deslocamento positivo na componente 2 implica mudança de inclinação na curva, fazendo com que os retornos nos prazos mais curtos se reduzam e nos mais longos se elevem. Esta componente, de inclinação, explica $12,78 \%$ da variação do sistema. Os fatores das componentes 3 e 4 são mais difusos e não aparentam representar claramente algum fato estilizado. Ainda assim, podemos ver em ambas (muito mais na 4 do que na 3) uma certa tendência de os valores crescerem até o meio da curva e depois decrescerem do meio para o final. Um deslocamento nestas componentes mudaria a convexidade da curva, portanto. As componentes 3 e 4 conjuntamente são responsáveis por explicar $9,1 \%$ da variabilidade. Para observar estes e outros comportamentos das componentes ver a Figura 5.1, que mostra os pesos das séries no plano das componentes, duas a duas.

Uma outra forma de visualizar as séries no espaço das componentes é rotacionando as componentes, para que elas estejam alinhadas com a máxima variação das séries. Fazendo isso, e apresentando um gráfico com as três primeiras componentes, temos a Figura 5.2 abaixo. Nota-se que a componente 3, quando rotacionada, explica em grande maneira, as séries de prefixados. A componente 2, as séries de índices de preços de longa duração e a componente 1 as séries de índices de preços de curta duração. Mesmo após a rotação segundo o critério VARIMAX, as séries de índices de preços 


\begin{tabular}{|c|c|c|c|c|c|c|c|c|c|c|}
\hline & $C P_{1}$ & $C P_{2}$ & $C P_{3}$ & $C P_{4}$ & $C P_{5}$ & $C P_{6}$ & $C P_{7}$ & $C P_{8}$ & $C P_{9}$ & $C P_{10}$ \\
\hline Pré ${ }_{1 A}$ & 0.2860 & -0.3844 & -0.2146 & -0.6661 & -0.2629 & -0.7070 & -0.2084 & -0.3765 & -0.1173 & 0.1464 \\
\hline$I P C A_{2}$ & 0.3145 & -0.1958 & -0.5341 & 0.1745 & 0.3278 & 0.4504 & -0.2727 & 0.2662 & 0.3023 & -0.1256 \\
\hline $\operatorname{Pré}_{2 A}$ & 3339 & -0.2906 & 0.2126 & -0.2347 & -0.4701 & -0.9363 & 0.3231 & 0.4849 & 0.5751 & -0.5943 \\
\hline$I P C A_{3 A}$ & 0.3420 & -0.1101 & -0.3421 & 0.2940 & 0.1610 & -0.1562 & 0.3029 & -0.1942 & -0.6981 & 0.1884 \\
\hline $\operatorname{Pré}_{3 A}$ & 0.3349 & -0.2053 & 0.4203 & 0.3338 & 0.1050 & 0.9289 & 0.1611 & 0.2884 & 0.3631 & 0.7392 \\
\hline$I P C A_{5}$ & 0.3476 & 0.5610 & -0.1315 & 0.3772 & 0.2332 & -0.5153 & 0.1492 & -0.2183 & 0.5711 & -0.1997 \\
\hline $\operatorname{Pré}_{5 A}$ & 0.3192 & -0.1226 & 0.5587 & 0.2338 & 0.2220 & 0.2017 & -0.3616 & -0.4656 & -0.2850 & -0.2791 \\
\hline$I P C A_{1}$ & 0.3199 & 0.3271 & 0.1422 & 0.1564 & -0.6606 & 0.1255 & -0.3984 & 0.2876 & -0.2689 & 0.1093 \\
\hline$I P C A_{20 A}$ & 0.2881 & 0.5083 & 0.1643 & -0.2256 & -0.4100 & 0.5091 & 0.5139 & -0.2538 & 0.1354 & -0.3641 \\
\hline$I P C A_{30 A}$ & 0.2657 & 0.5400 & -0.1149 & -0.3331 & 0.4925 & -0.4216 & -0.2902 & 0.1412 & -0.4695 & -0.2997 \\
\hline
\end{tabular}

Tabela 5.2: Pesos das componentes.
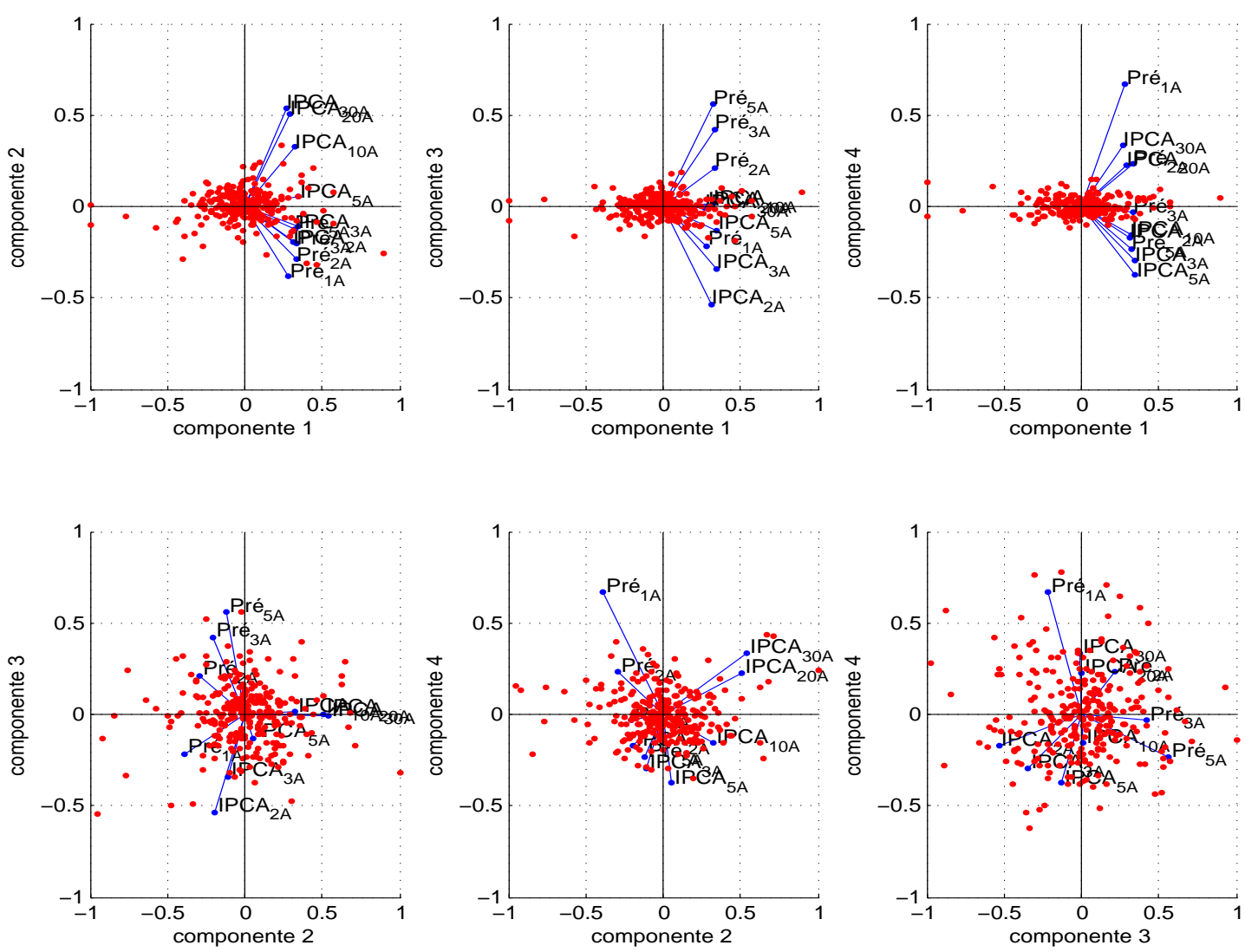

Figura 5.1: Séries no espaço das componentes duas a duas.

com prazo intermediário (IPCA $10 A$ e IPCA $20 A$ ) aparentam ser explicadas por uma composição das componentes 1 e 2 .

Conhecidas as componentes, podemos estimar um modelo GARCH univariado para cada uma das quatro primeiras componentes(ordenadas de forma decrescente por seus autovalores). Antes de fazê-lo, observemos os gráficos da FAC e FACP das componentes.

Abaixo seguem os modelos ajustados para as quatro componentes em análise. 


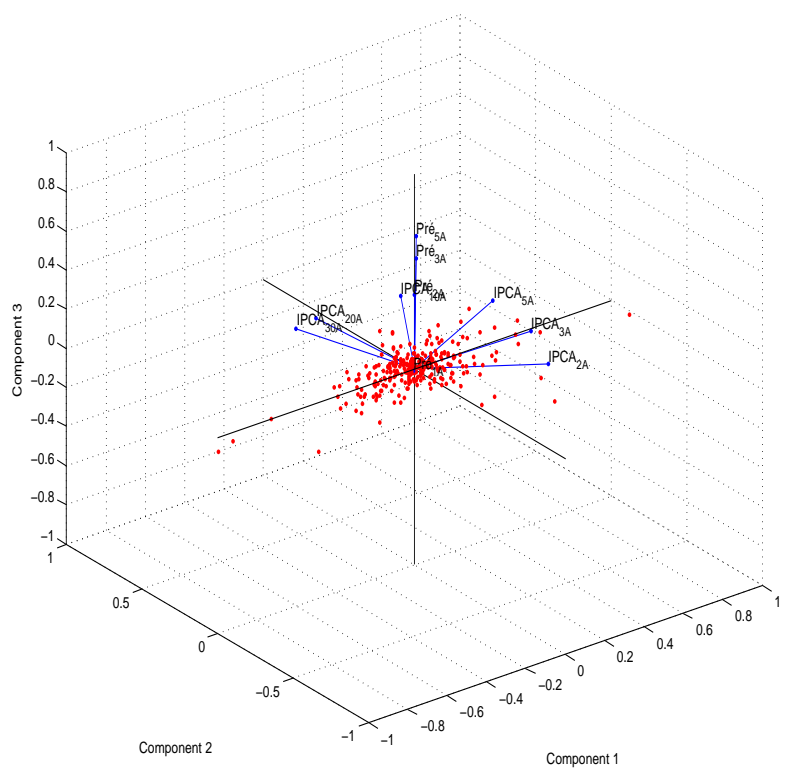

Figura 5.2: Séries no espaço das três primeiras compoentes.

\subsubsection{Ajuste do modelo GARCH}

\section{Componente 1}

Observamos na Figura 5.3 a presença de autocorrelação entre os retornos e entre os retornos ao quadrado. Em relação aos retornos, vemos que a um nível de significância de $5 \%$, há correlações significativas até a segunda defasagem. Quanto aos retornos ao quadrado, há autocorrelações e autocorrelações parciais signficativas mesmo após a defasagem 10.
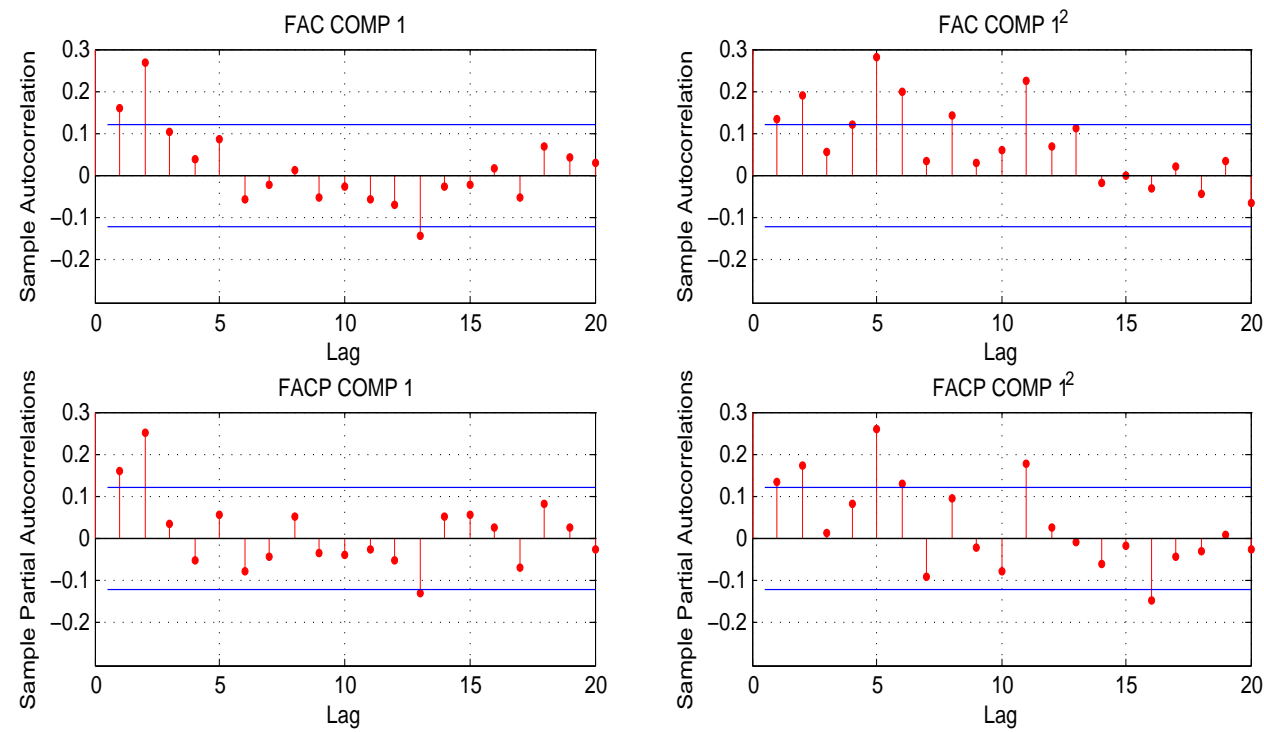

Figura 5.3: Função de autocorrelação parcial dos retornos e dos retornos ao quadrado da componente 1 .

Ao fazermos o ajuste dos coeficientes do modelo no MATLAB, maximizando a função de verossimilhança, conforme equação 4.11, e buscando o melhor ajuste, segundo o critério de informação de Akaike e o critério de informação Bayesiano, chegamos aos coeficientes para o modelo ARMAGARCH da Tabela 5.3. Apesar de a função de autocorrelação do retorno ao quadrado sugerir ordens 
altas para a parte GARCH do modelo, as ordens que minimizam os critérios mencionados são estas postas em nosso resultado. ${ }^{1}$ Ressalta-se que a distribuição que melhor promoveu este ajuste foi a t-Student com 4 graus de liberdade.

\begin{tabular}{|r|r|r|r|}
\hline Parâmetro & Estimativa & Erro padrão & Est. T \\
\hline AR(1) & 0,6888 & 0,1762 & 3,9092 \\
MA(1) & $-0,5309$ & 0,2077 & $-2,5555$ \\
GARCH(1) & 0,8056 & 0,0617 & 13,0429 \\
ARCH(1) & 0,1943 & 0,0774 & 2,5097 \\
\hline
\end{tabular}

Tabela 5.3: Parâmetros do ajuste da componente 1.

Para testar as autocorrelações dos resíduos e dos resíduos ao quadrado estimados, realizamos o teste Box-Pierce-Ljung proposto por Ljung e Box (1978). Ao fazê-lo, com o Matlab, obtemos um p-valor que denota não podermos rejeitar a hipótese de que se trata de um ruído branco. Por fim, apresentamos na Figura 5.4 os gráficos da função de autocorrelação e autocorrelação parcial dos resíduos ao quadrado da componente 1 , que mostram não haver mais heterocedasticidade condicional. Observando o gráfico dos resíduos, verificou-se não haver autocorrelações significativas nos resíduos ajustados.
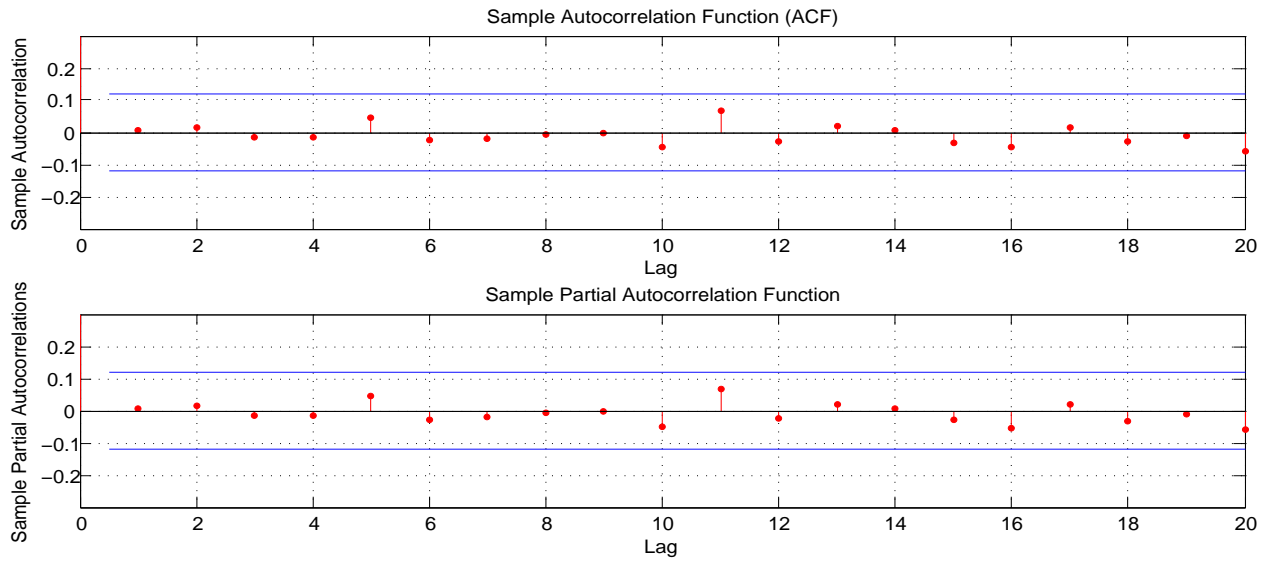

Figura 5.4: Função de autocorrelação e autocorrelação parcial dos resíduos ao quadrado do ajuste da componente 1 .

\section{Componente 2}

Observamos na Figura 5.5 a presença de autocorrelação entre os retornos na defasagem 1. Nos retornos ao quadrado, há autocorrelações significativas a $5 \%$ nas defasagens 1 e 12 . Ao fazermos o ajuste dos coeficientes e buscarmos as ordens do modelo, que atendam aos critérios mencionados no ajuste da primeira componente, obtemos o resultado da Tabela 5.4. O modelo obtido é coerente com a informação das funções da Figura 5.5. Exceção feita à ordem da parte GARCH, que ficou em (1), pois, a exemplo do que ocorreu anteriormente, ao aumentar o número de parâmetros, faz com que os critérios de Akaike e Bayesiano penalizem sobremaneira o aumento da quantidade de parâmetros, de tal sorte que tal efeito não se sobreponha ao aumento do valor do estimador de máxima verossimilhança. ${ }^{2}$

\footnotetext{
${ }^{1}$ Ver [Ped06], pg. 166, para métodos de identificação baseados em uma função penalizadora.

${ }^{2}$ Ver [Ped06], pg. 167, para correções que buscam melhorar o comportamento do AIC
} 

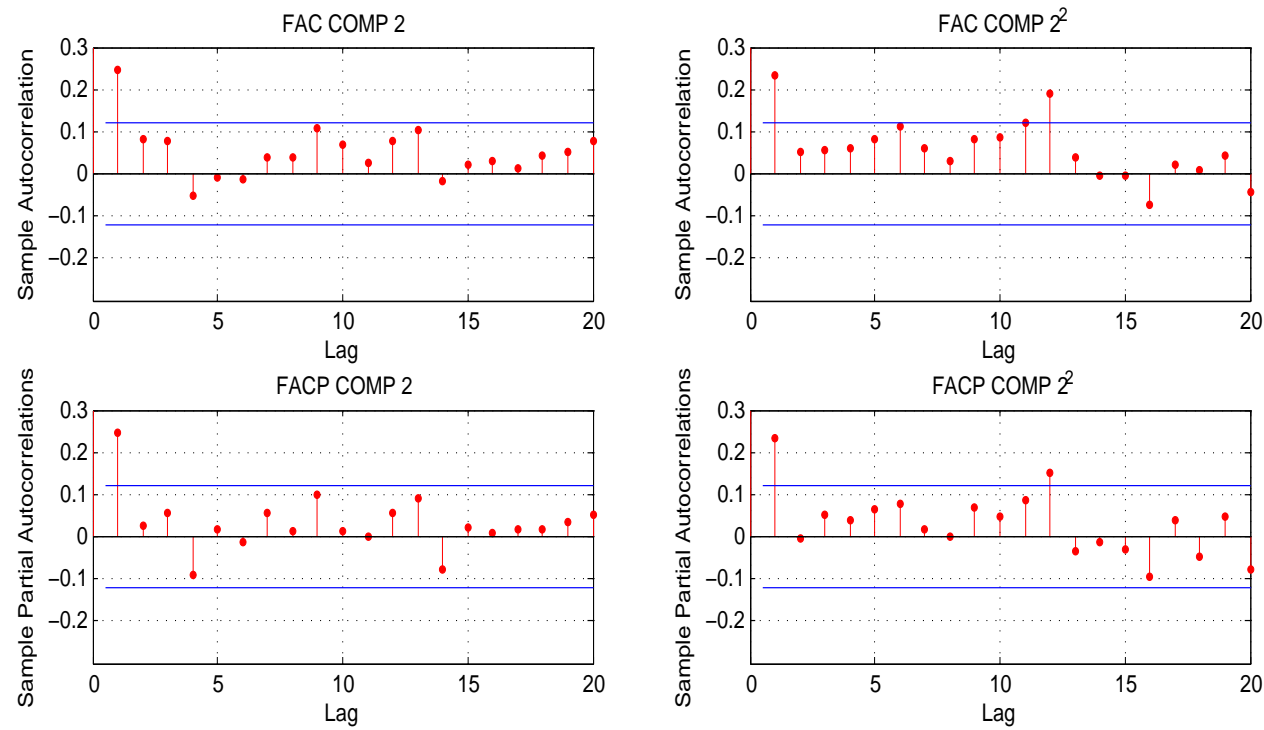

Figura 5.5: Função de autocorrelação parcial dos retornos ao quadrado da componente 2 .

\begin{tabular}{|r|r|r|r|}
\hline Parâmetro & Estimativa & Erro padrão & Est. T \\
\hline AR(1) & 0,2557 & 0,0577 & 4.4322 \\
GARCH(1) & 0,7678 & 0,0939 & 8,1759 \\
ARCH(1) & 0,1684 & 0,0851 & 1,9791 \\
\hline
\end{tabular}

Tabela 5.4: Parâmetros do ajuste da componente 2.

Ao realizar o teste Box-Pierce-Ljung, para testar as autocorrelações dos resíduos estimados também não podemos rejeitar a hipótese de que se trata de um ruído branco. Abaixo apresentamos na Figura 5.6 os gráficos da função de autocorrelação e autocorrelação parcial dos resíduos ao quadrado da componente 2, que mostram ter sido um bom ajuste. Graficamente também verificouse não haver mais autocorrelação nos resíduos. 

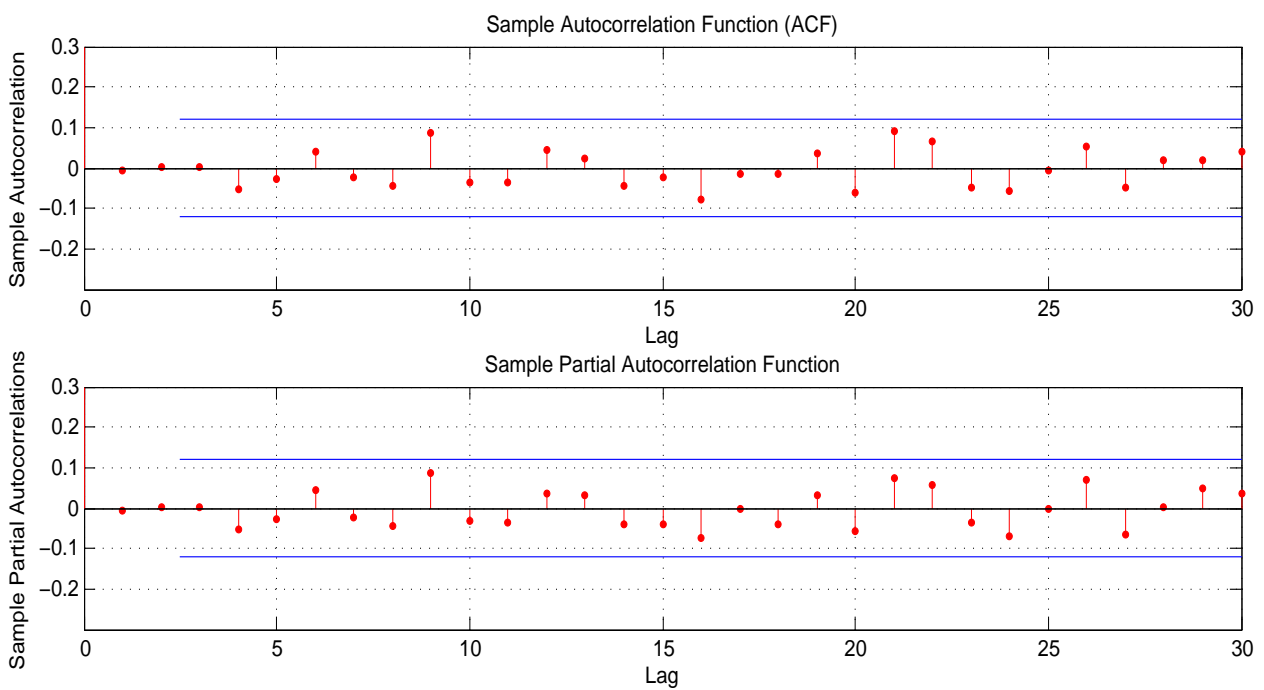

Figura 5.6: Função de autocorrelação e autocorrelação parcial dos resíduos ao quadrado do ajuste da componente 2 .

\section{Componente 3}

Observamos na Figura 5.7 a presença de autocorrelação entre os retornos ao quadrado, apenas, o que sugere ordem zero na parte ARMA do modelo. De fato, ao fazermos o ajuste, chegamos a coeficientes signficantes na parte GARCH, conforme Tabela 5.5. O teste Box-Pierce-Ljung também indicou adequação do modelo ajustado para esta componente. A Figura 5.8 apresenta a funções de autocorrelação e autocorrelação parcial dos resíduos ao quadrado. Verifica-se não haver coeficientes significativos. Poder-se-ia consider diminuir o coeficiente da defasagem 6(sobre a linha de significância) com um modelo $\operatorname{GARCH}(1,6)$, porém, em nome de ter um modelo o mais simples possível e, sobretudo por conta de o modelo $\operatorname{GARCH}(1,1)$ ter se verificado adequado segundo o teste Box-Pierce-Ljung, o materemos desta forma.
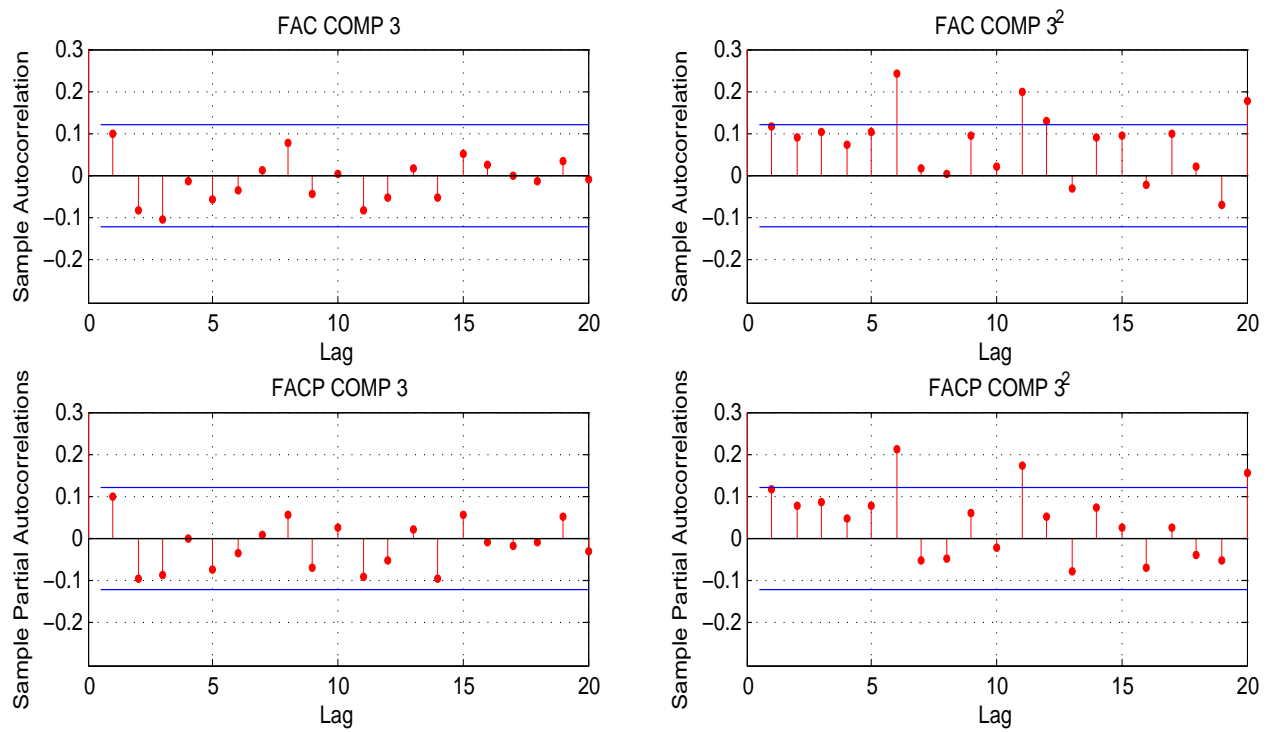

Figura 5.7: Função de autocorrelação parcial dos retornos e dos retornos ao quadrado da componente 3 . 


\begin{tabular}{|r|r|r|r|}
\hline Parâmetro & Estimativa & Erro padrão & Est. T \\
\hline GARCH(1) & 0,8879 & 0,0551 & 16,1252 \\
ARCH(1) & 0,0815 & 0,0393 & 2,0759 \\
\hline
\end{tabular}

Tabela 5.5: Parâmetros do ajuste da componente 3.
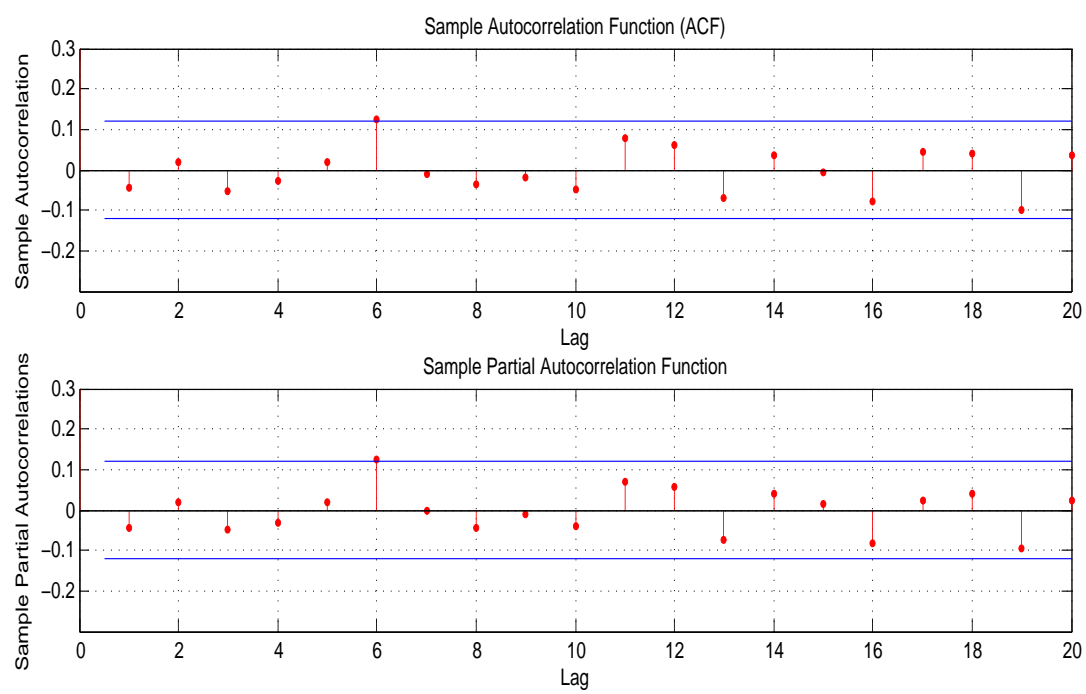

Figura 5.8: Função de autocorrelação e autocorrelação parcial dos resíduos ao quadrado do ajuste da componente 3 .

Observamos na Figura 5.9 a presença de autocorrelação entre os retornos ao quadrado e autocorrelações dos retornos apenas a partir de ordens mais altas. Aqui, fez-se o ajuste de forma análoga ao que foi feito nas três primeiras componentes, tentando sempre deixar o modelo com o menor número possível de parâmetros. Abaixo os resultados do modelo ajustado:
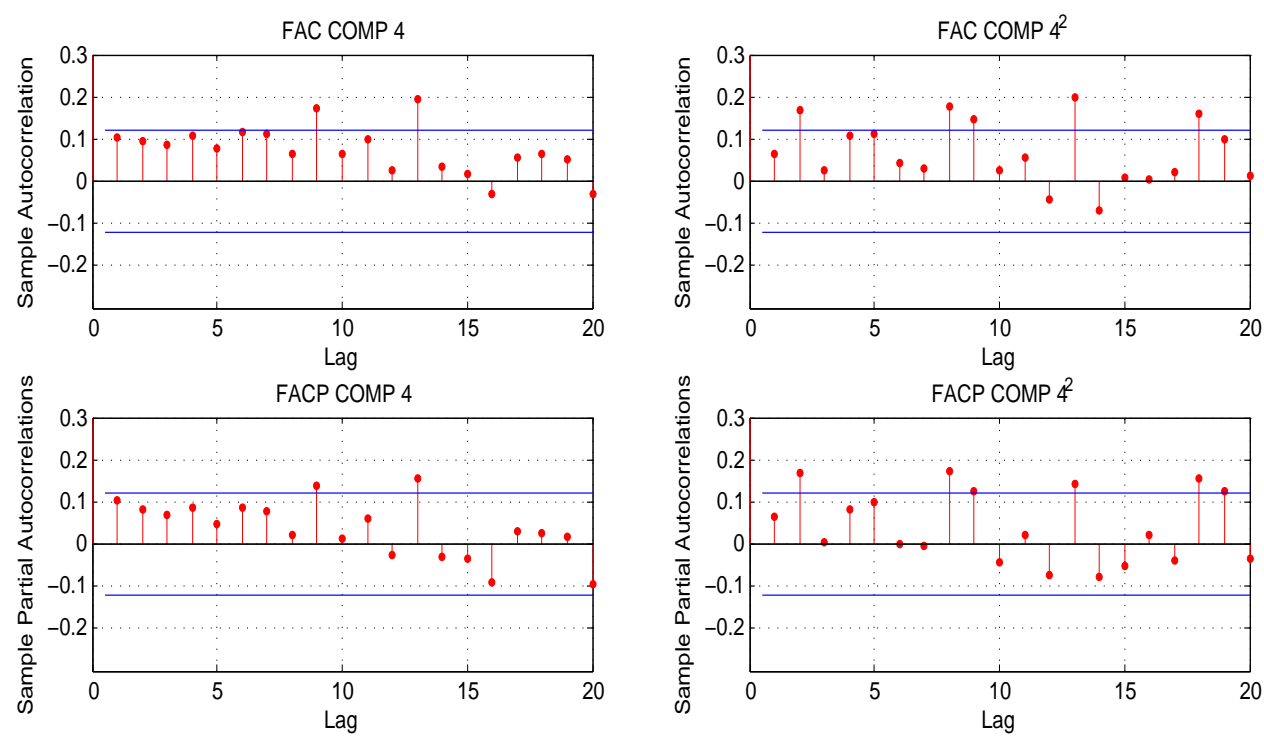

Figura 5.9: Função de autocorrelação parcial dos retornos e dos retornos ao quadrado da componente 4 . 


\begin{tabular}{|r|r|r|r|}
\hline Parâmetro & Estimativa & Erro padrão & Est. T \\
\hline AR(1) & 0,8898 & 0,0473 & 18,7834 \\
AR(2) & 0,9037 & 0,0403 & 22,4007 \\
AR(3) & $-0,8888$ & 0,0426 & $-20,8539$ \\
MA(1) & $-0,8907$ & 0,0284 & $-31,2653$ \\
MA(2) & $-0,9304$ & 0,0110 & $-84,0797$ \\
MA(3) & 0,9589 & 0,0265 & 36,0943 \\
GARCH(1) & 0,8411 & 0,0863 & 9,7472 \\
ARCH(1) & 0,0944 & 0,0492 & 1,9186 \\
\hline
\end{tabular}

Tabela 5.6: Parâmetros do ajuste da componente 4.
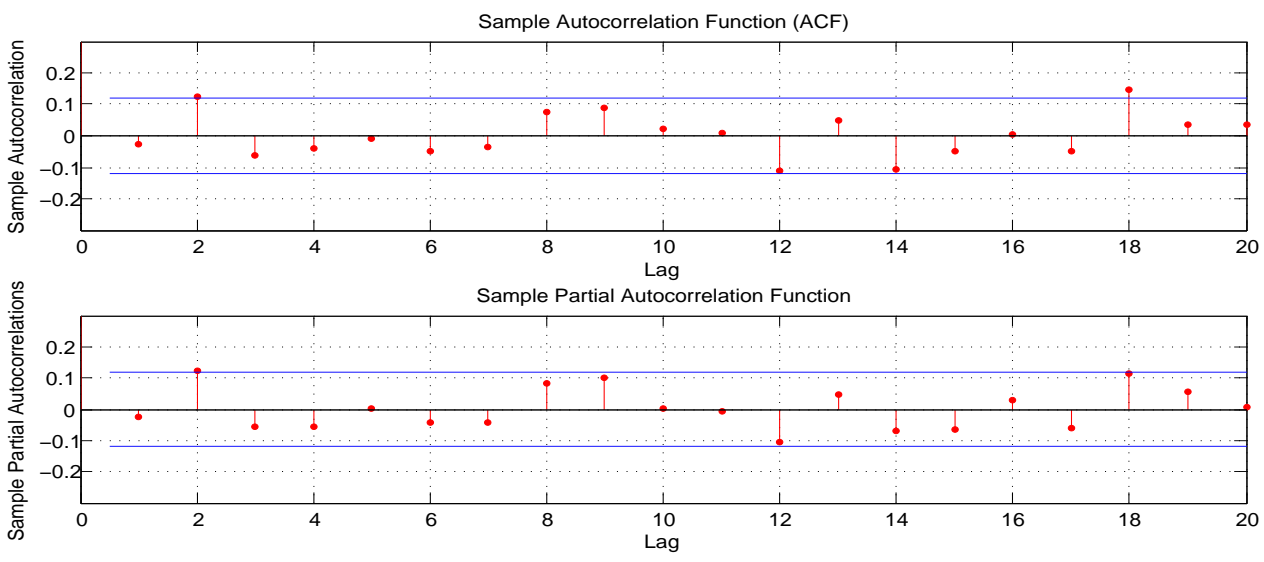

Figura 5.10: Função de autocorrelação e autocorrelação parcial dos resíduos ao quadrado do ajuste da componente 4 .

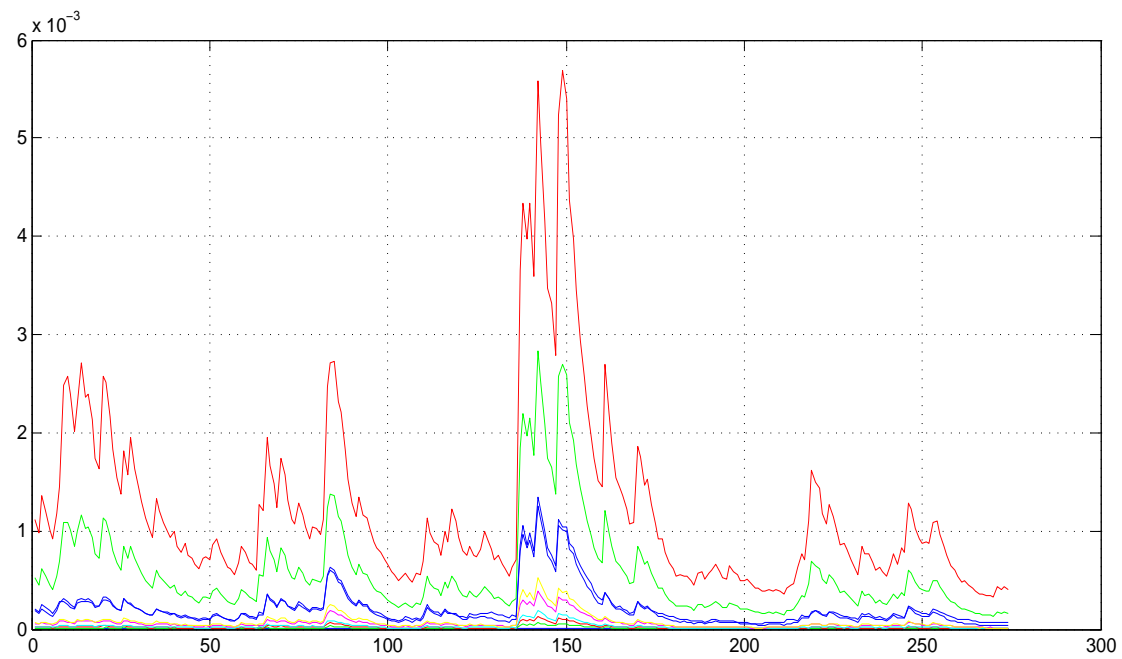

Figura 5.11: Variâncias estimadas das variáveis originais pelo modelo GARCH ortogonal .

Finalizada esta etapa, temos todos os parâmetros para construir as matriz de covariâncias $V_{t}$ em todos os passos, conforme em 4.7. Na Figura 5.11 vemos as variâncias das variáveis originais, ou 

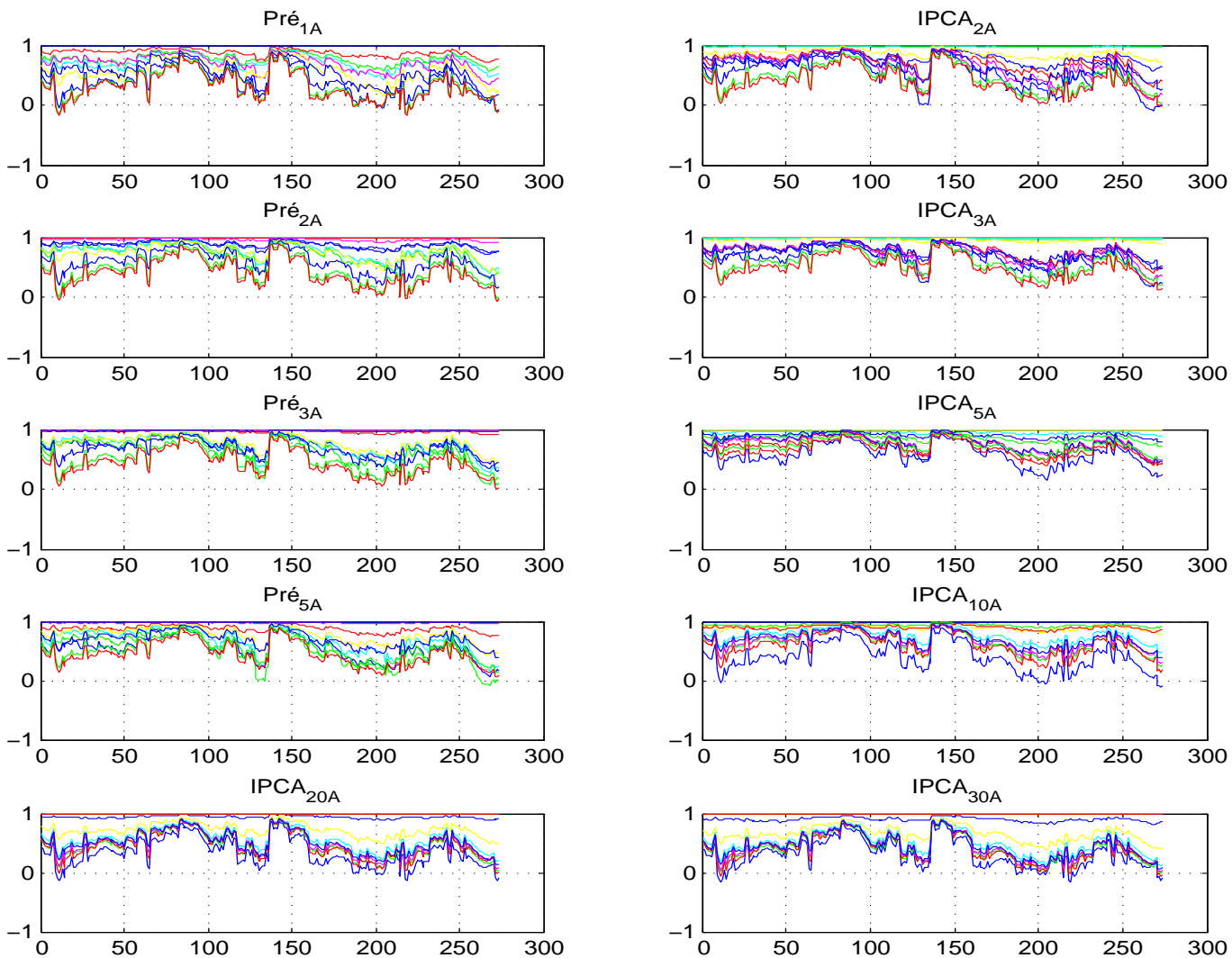

Figura 5.12: Correlações estimadas pelo modelo GARCH ortogonal de cada uma das variáveis originais em relação às demais.

seja, a diagonal da matriz $V_{t}$ em todos os passos. Analogamente, na Figura 5.12 temos as correlações de cada uma das séries com as demais. Observando cada uma delas, vemos, em primeiro lugar, que de fato se trata de um sistema altamente correlacionado. Vemos tambem que as séries de $I P C A_{20 A}$ e $I P C A_{30 A}$ são as menos correlacionadas com o restante do sistema, o que vai ao encontro do que ocorre de fato com estes títulos. 


\section{Variâncias Estimadas}
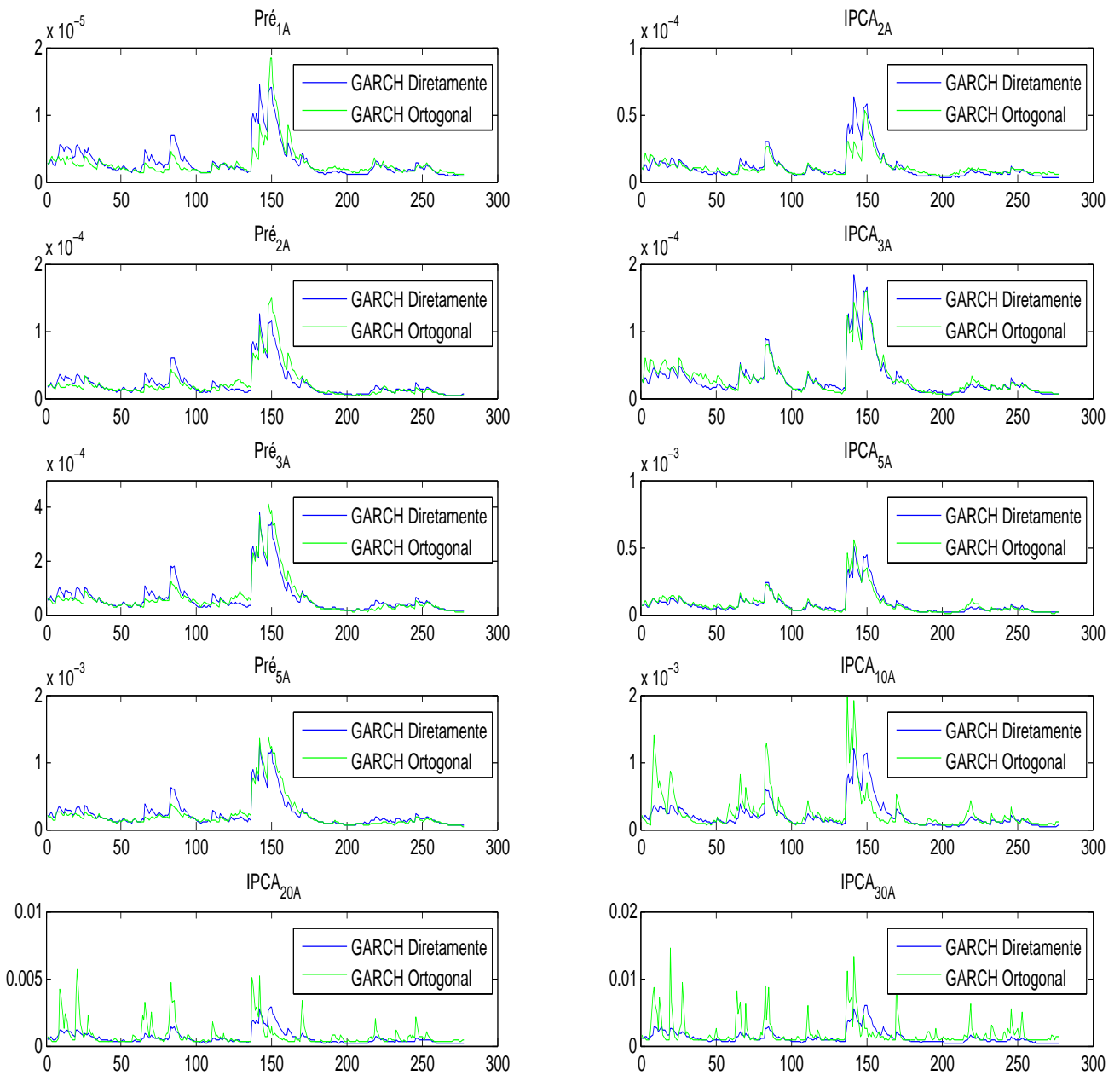

Figura 5.13: Variâncias Estimadas Diretamente e pelo Método Ortogonal.

No Gráfico 5.13, temos as variâncias condicionais estimadas diretamente nas séries e aquelas estimadas pelo método ortogonal. Vemos que pelo fato de as séries $I P C A_{10 A}, I P C A_{20 A}$ e $I P C A_{30 A}$ serem menos correlacionadas com o resto do sistema, o modelo GARCH Ortogonal funcionou menos eficientemente ao estimar a volatilidade destas três séries. Por conta disso, seria interessante lançar mão da técnica tratada no Capítulo $4.3 \mathrm{em}$ que se segmenta o sistema em categorias e buscar um melhor desempenho deste modelo ortogonal, criando uma categoria para os títulos com prazo igual ou superior a 10 anos. Nas demais séries, observa-se uma semelhança muito grande entre a variância condicional estimada diretamente e a estimada através do método ortogonal. 


\subsection{Black-Litterman}

\subsubsection{Visões Subjetivas}

Confome exposto no Capítulo 2, as visões de curto prazo do investidor podem ser expressas na forma da equação (2.8). Cada linha do vetor $P$ contém uma visão do investidor. Cabe observar que as visões podem se dar em termos de relações absolutas ou relativas. Em um primeiro exemplo, supondo que as visões sigam uma distribuição normal, pode-se imaginar que o investidor contemple as seguintes visões hipotéticas:

- Visão 1: A carteira de títulos vinculados ao IPCA supera o retorno da carteira de prefixados de $1 \%$ a $3 \%$ ao ano, com $95 \%$ de confiança.

- Visão 2: O conjunto dos 5 títulos mais longos superam o conjunto dos 5 mais curtos em $2 \%$ a $3 \%$ ao ano, com $90 \%$ de confiança.

- Visão 3: O retorno do título de 30 anos vinculado ao IPCA fica entre $10 \%$ a $14 \%$ ao ano, com $68 \%$ de confiança.

A visão 1 é expressa na forma de uma relação entre dois grupos de ativos. Espera-se que o retorno do grupo de títulos vinculados ao IPCA (grupo 1) supere o retorno do grupo 2, formado por títulos prefixados, em $2 \%$ na média. Ou seja: $E\left[\left(\right.\right.$ Retorno $_{\text {grupo } 1}-$ Retornogrupo $\left.\left._{2}\right)\right]=2 \%$. O retorno do grupo 1 é dado pela soma dos retornos dos títulos vinculados ao IPCA, poderados pela proporção de cada um dos títulos neste grupo. Da mesma forma, as proporções dos títulos prefixados no grupo 2 podem ser encontradas (estes valores estão na linha 1 de $P$ ) e o retorno deste grupo calculado. A estes valores atribiu-se sinal negativo para construir a diferença entre retornos. Na visão 2 , o grupo 1 será compostos pelos 5 títulos mais longos e o grupo 2 pelos 5 títulos mais curtos. A segunda linha de $P$ contém as proporções dos ativos em cada grupo, sendo que as proporções do grupo 2 estão com o sinal negativo para que: $E\left[\left(\right.\right.$ Retorno $_{\text {grupo } 1}-$ Retorno $\left.\left._{\text {grupo } 2}\right)\right]=2,5 \%$. A terceira visão indica a crença no retorno esperado do título de 30 anos em $12 \%$ ao ano.

As proporções em cada grupo podem ser obtidas a partir da Tabela 3.1. A título de exemplo, tomemos a visão 1. A partipação do $\mathrm{IPCA}_{2 a n o s}$ no grupo 1 (títulos vinculados ao IPCA) é a razão entre sua partipação na carteira total $(2 \%)$, e a partipação total dos títulos vinculados ao IPCA (18\%). Analogamente, as demais proporções podem ser obtidas. Basta considerar a partipação do título e do grupo ao qual faz parte em cada visão. A visão 1 considera como grupo 1 os títulos vinculados ao IPCA, cujo total na carteira é de $18 \%$, e, grupo 2, os prefixados, cuja partipação é de $82 \%$. A visão 2 estabelece a divisão de grupos segundo o critério de maturação. No grupo 1, os títulos mais curtos, cuja partipação é de $69 \%$, e os mais longos no grupo 2, com partipação de $31 \%$. As duas visões anteriores são do tipo relativa. A terceira é do tipo absoluta, pois expressa a crença na rentabilidade de um único ativo ou grupo.

A incerteza na visão 1 implica a crença em um intervalo de $1 \%$ a $3 \%$ ao ano, com $95 \%$ de confiança, tem implicito desvio padrão de $0,5 \%$, pois dois desvios representam um retorno de $1 \%$. Analogamente, a visão 2 tem implícito um desvio-padrão de 0,31\%, pois 1,667 desvio representa um retorno de 0,5\%. Analogamente a terceira visão tem desvio padrão implícito de 2,0\%. Assim, temos a equação (2.8), para nosso caso hipotético:

$$
P .\left(\begin{array}{l}
E\left(R_{P r e_{1 A}}\right) \\
E\left(R_{I P C A_{2 A}}\right) \\
\vdots \\
E\left(R_{I P C A_{30 A}}\right)
\end{array}\right)=\left(\begin{array}{r}
2,00 \% \\
2,50 \% \\
12,00 \%
\end{array}\right)+\left(\begin{array}{l}
0,50 \%^{2} \\
0,31 \%^{2} \\
2,00 \%^{2}
\end{array}\right)
$$


Sendo:

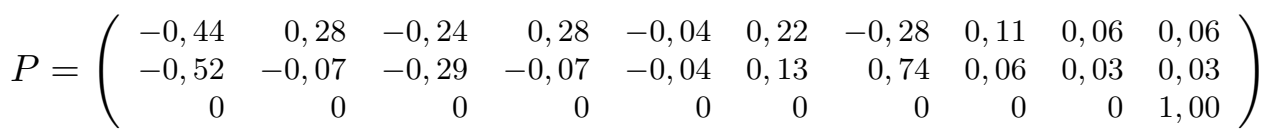

Com visões relativas ou absolutas, o investidor pode estabelecer de zero a $k$ visões para expressar sua visão de curto prazo.

Vemos na Figura 5.14 que a carteira se alterou de forma coerente com as visões de curto-prazo. Em primeiro lugar, em função da visão 1, os retornos dos prefixados tenderam a se reduzir, ou crescer menos, comparativamente aos retornos dos títulos vinculados à inflação. Vemos também que os títulos mais longos apresentaram incremento no retorno superior aos de menor prazo. Isto se dá por conta da visão 2. A visão 3 apenas faz aumentar o retorno do título de 30 anos. O retorno do título prefixado de 5 anos aumentou moderadamente por conta das visões 1 e 2, que trouxeram a este título impactos com sentidos contrários. Com magnitudes diferentes, o mesmo ocorreu com os títulos prefixados de prazo inferior. Ressalta-se que nas rotinas de otimização incluímos a restrição de não pode haver posição vendida. Ao analisar os pesos da carteira após incluir a visão de curto prazo do investidor, é necessário lembrar que além dos retornos também está em jogo a matriz de covariâncias da carteira. Assim, por conta das correlações e da diversificação da carteira, o aumento na participação de um ativo pode implicar o aumento da participação de outro, mesmo que o retorno deste segundo não tenha se alterado.

Ainda na Figura 5.14, vemos a composição da carteira antes e após incorporar as visões subjetivas do investidor, com a restrição de não ser permitido criar posições vendidas, isto é: $0 \leq w_{i} \leq 1 \mathrm{e}$ $\sum_{k}^{i=1} w_{i}=1$. Devido ao fato de o sistema ser todo positivamente correlacionado, certamente teríamos posições vendidas se retirássemos esta restrição. A confiança nas visões, as constantes $\tau$ e $\delta$ também influenciam na concentração nos vencimentos. Ao mesmo tempo, sabemos que a composição da carteira só se altera para aqueles ativos sobre os quais existem visões a respeito, fazendo com que o resultado do modelo B-L seja muito mais estável do que aquele obtido com os modelos tradicionais de média-variância. Em nossa aplicação todos os percentuais variaram pois as Visões 1 e 2 incluem todos os títulos.

A Figura 5.15 apresenta a relação de retorno e risco da carteira antes e após incorporar visões de curto prazo. Apresenta também a fronteira eficiente dos ativos antes e depois. A fronteira eficiente denota os pontos de mínima variância para um determinado retorno, obtido com uma certa composição $w$ de ativos. Os pontos no interior da região delimitada são composições da carteira cuja relação retorno x risco é inferior aos da fronteira. Os pontos externos à região não são factíveis para os possíveis valores de $w$, dadas as restrições impostas pela otimização. Vemos que, ao incorporar as visões, a fronteira se moveu para cima e para a direita, deslocando-se, portanto, no sentido do aumento da utilidade do investidor. 

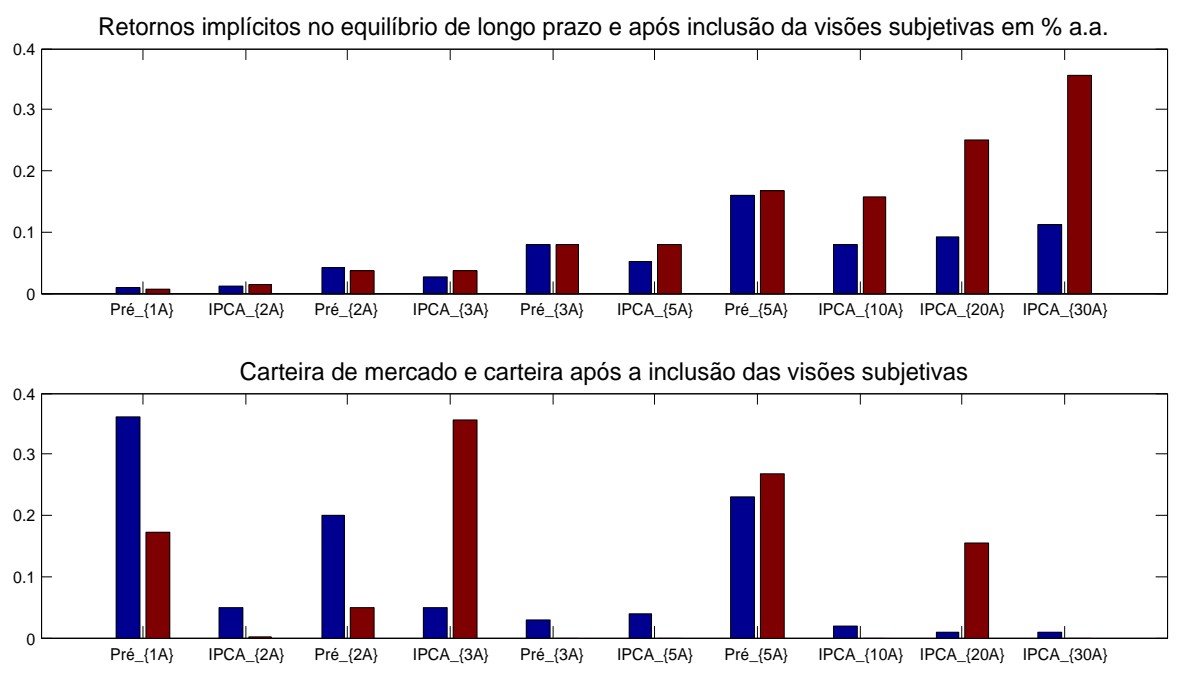

Figura 5.14: Comparação do retorno e da composição da carteira antes e após incorporar visão subjetiva do investidor.

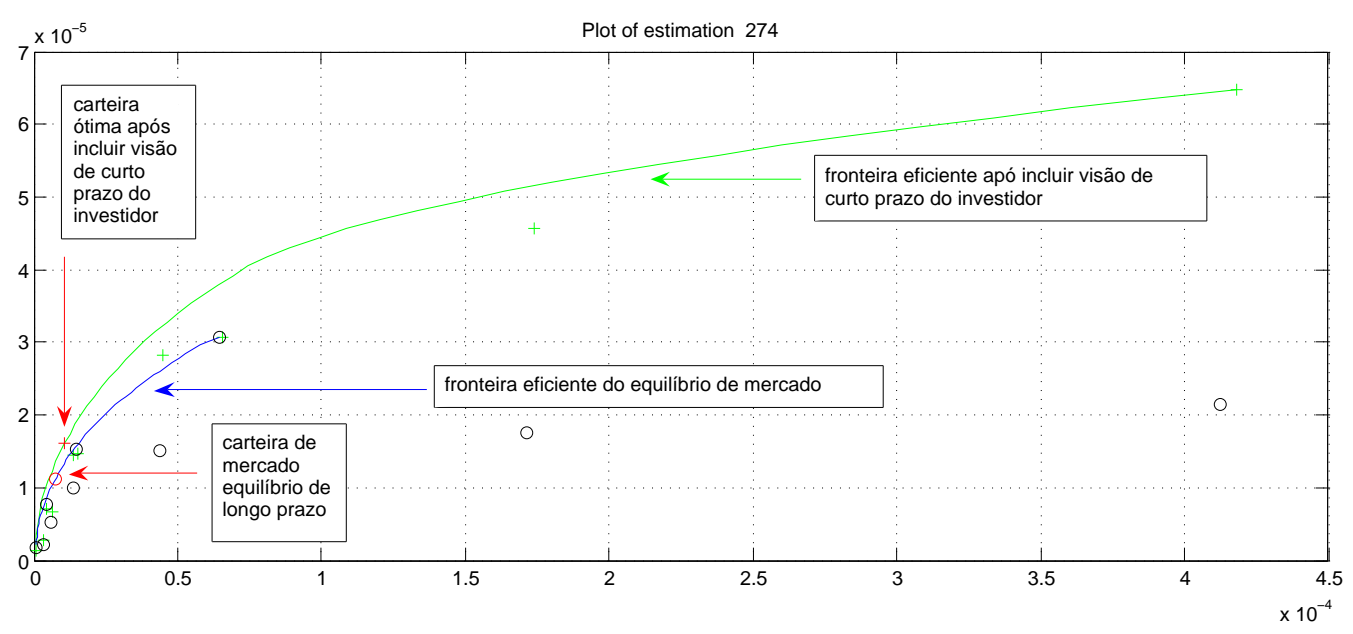

Figura 5.15: Carteira de longo-prazo (o) e carteira ótima (+) após incorporar visões de curto-prazo do investidor.

\subsubsection{Visões A Partir de um Modelo GARCH Ortogonal}

Após verificarmos na Sessão 5.2.1 como as visões de curto prazo podem ser expressas, e como são combinadas com a carteia de mercado em equilíbrio, nesta sessão nosso objetivo é utilizar o modelo de séries temporais para gerar visões de curto prazo, e verificar se os resultados obtidos são consistentes com o resultado esperado, ou seja, verificar se o modelo GARCH Ortogonal é capaz de gerar visões(previsões) que levem a carteiras cujo desempenho, em termos de risco e retorno, seja superior ao desempenho da carteira de equilíbrio de mercado. Uma experiência similar, de obter visões a partir de um modelo de séries temporais, pode ser encontrada em Beach e Orlov(2006) [Ste]. A expectativa de que tal modelo leve a desempenho superior reside no fato de o modelo GARCH ser uma reconhecida ferramenta capaz de capturar a dinâmica de retornos em suas diversas propriedades, que usualmente se traduzem nos fatos estilizados observados em séries financeiras, tais como a heterocedasticidade, a assimetria, o cluster de volatilidade, dentre outros. Ver Sessão 4.4 
Para tanto, na Equação (2.8), $P \mu=Q+\epsilon^{(v)}$, as visões de curto prazo do investidor serão substituídas por retornos e matrizes de covariância estimadas por modelo de séries temporais, conforme estimação GARCH ortogonal, tratada no Capítulo 4, e modelo GARCH ajustado na Sessão 5.1.2.

Com o modelo previamente ajustado para uma série de 274 observações, partiremos da carteira de mercado estimada na observação de número 274 e faremos previsões dos retornos e variâncias para as quatro semanas seguintes $(275,276,277$ e 278). As previsões das variâncias foram obtidas utilizamos o modelo GARCH ajustado para as quatro componentes e transformando-as nas variâncias das variáveis originais, com a Equação (4.6),da mesma forma que realizado na estimação GARCH ortogonal, conforme descrito no Capítulo 4.2. Aproveitando a estrutura de ortogonalização, fizemos, com o modelo ajustado, previsões das quatro componentes principais consideradas e as transformamos nas previsões dos retornos das variáveis originais através da Equação (4.5).

Os retornos e variâncias previstos serão as visões geradas pelo modelo GARCH ajustado. Tais visões, uma vez mescladas com o equilíbrio de mercado existente na observação 274 através do modelo Black-Litterman, resultarão no vetor de retornos e matriz de covariâncias a posteriori. Em posse destas, poderemos conhecer a composição da carteira ótima em cada uma das quatro semanas, para as quais fizemos previsões. Tendo em vista que cohecemos os retornos efetivamente realizados nas semanas em análise, podemos verificar se o resultado das carteiras obtidas têm desempenho superior ao equilíbrio de mercado. Para fazer esta verificação, calcularemos a razão do retorno e do desvio padrão das carteiras em cada uma das previsões. Esta razão, conhecida por índice de Sharpe, é uma difundida ferramenta para avaliar se o desempenho da mesma está adequado, isto é, se o retorno é compatível com o risco da mesma. Naturalmente, a interpretação deste índice é bastante direta: quanto maior o índice, mais favorárel para o investidor a relação risco x retorno. Para este e outros índices de avaliação de carteiras, ver Sharpe(2007) [Sha07]. Em seguida, agruparemos os resultados das carteiras estimadas com os resultados da carteira de mercado em todos os passos e observaremos se o índice de Sharpe das carteiras geradas pelo modelo GARCH é superior ao índice de Sharpe da carteira de mercado.

\subsubsection{Resultados}

Da teoria de finanças, sabe-se que superar consistentemente a carteira de mercado não é tarefa trivial, pois, dentre outras razões, o mercado tende a incorporar, mais cedo ou mais tarde, todas as informações e modelos disponíveis, tornando a carteira de equilíbrio de mercado mais eficiente à medida em que o faz. Outra importante consideração a ser feita, antes de interpretar o resultado propriamente, é a respeito da curva de juros no mercado brasileiro. Há muitos anos esta curva se apresenta invertida, isto é, juros mais altos na parte inicial da curva do que no restante da mesma. Este formato se contrapõe à intuição de que o emissor tem que compensar o investidor pela liquidez, volatilidade, em suma, pelos riscos de mercado, que são crescentes com a duração do título mas, ao mesmo tempo, reflete fielmente a expectativa dos agentes em relação ao futuro da inflação e das taxas de juros. Assim sendo, muitas vezes a estratégia de se concentar no curto prazo é uma estratégia dominante em relação às demais, ao oferecer maior retorno e menor volatilidade, e, por conta disso, não é surpesa que a carteira de mercado tenha uma razoável concentração nos prazos mais curtos.

Apesar das considerações acima, há outros elementos presentes em uma curva de juros que tornam o seu estudo bastante rico e trazem oportunidades além da construção de carteiras concentradas no curto prazo. Um desses elementos é a segmentação de mercado em partes específicas curva. Tesourarias, investidores estrangeiros, indústria de fundos e investidores institucionais costumam se concentrar em partes específicas da curva. Dado que cada um destes grupos tem mandatos distintos e, muitas vezes, expectativas distintas, uma vez que se especializam em seu segmento de 
mercado, um mesmo evento econômico pode trazer reações distintas nos diversos segmentos de investidores e, consequentemente, impactos distintos ao longo da curva. Em outras palavras, por causa da segmentação, o impacto de uma nova informação não necessariamente causa sempre maior volatilidade à ponta longa da curva. Há ainda eventos que, por si só, afetam partes específicas da curva. Da mesma forma, a evolução do formato da curva pode permitir que a parte longa ou intermediária também ofereçam retornos superiores aos retornos da parte curta, em alguns momentos.

O objetivo das considerações acima é esclarecer que superar a carteira de mercado em termos do risco e retorno é naturalmente difícil. Fazê-lo em um mercado com as particularidades do mercado brasileiro, pode ser ainda mais difícil, mas que, todavia, há oportunidades que podem ser exploradas. Por conta da existência de tais condições e oportunidades, surgiu a idéia de utilizar o modelo GARCH para gerar as visões (retorno e variância) e verificar o desempenho das carteiras geradas pelas previsões deste modelo. Este é o objetivo desta sessão.

Seguindo os passos da sessão anterior, pudemos encontrar a carteira eficiente em cada uma das previsões, segundo as visões de curto-prazo dadas pelo modelo GARCH, conforme exposto nas Figuras 5.16, 5.17, 5.18 e 5.19. Nas quatro previsões do modelo GARCH, observarmos que a carteira de equilíbrio resultante ganha em retorno, mantendo praticamente constante o desvio padrão, o que graficamente já indica a melhoria no índice de Sharpe. Além disso, por acaso, os títulos mais longos apresentaram retornos inferiores nas semanas em estudo (Ver Gráfico 3.4), o que foi corretamente previsto pelo modelo e, consequentemente, as carteiras ótimas resultantes excluíram tais títulos de sua composição (basta observar que estes títulos estão fora da fronteira eficiente). Por fim, com as carteiras encontradas, e com os reais retornos em cada uma das semanas, pudemos calcular o índice de Sharpe nas semanas 275, 276, 277 e 278 da carteira gerada pelo modelo em análise, e comparar com o índice de Sharpe da carteira de mercado nas mesmas semanas. O resultado segue na Figura 5.20 .

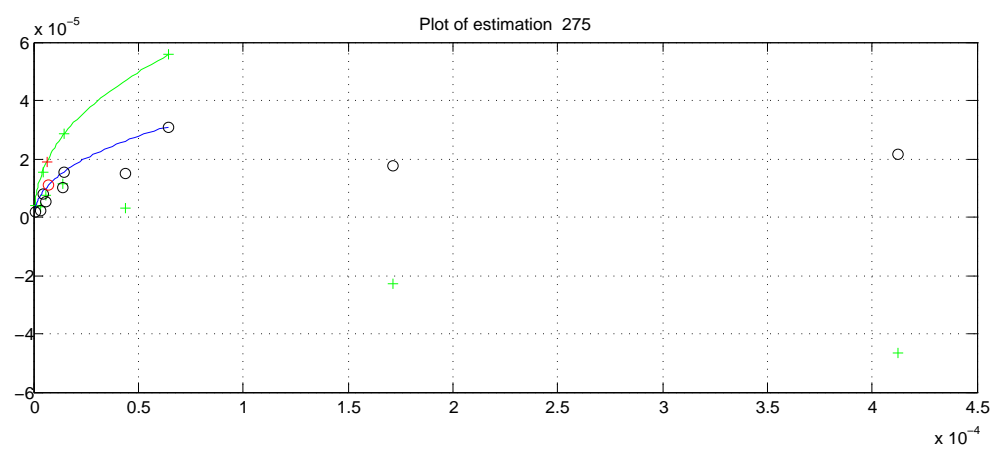

Figura 5.16: Fronteira eficiente da previsão 275. 


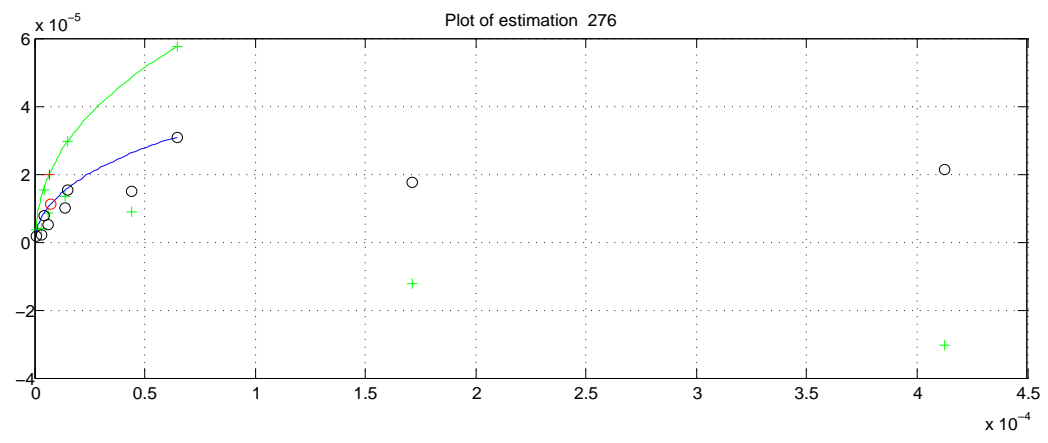

Figura 5.17: Fronteira eficiente da previsão 276.

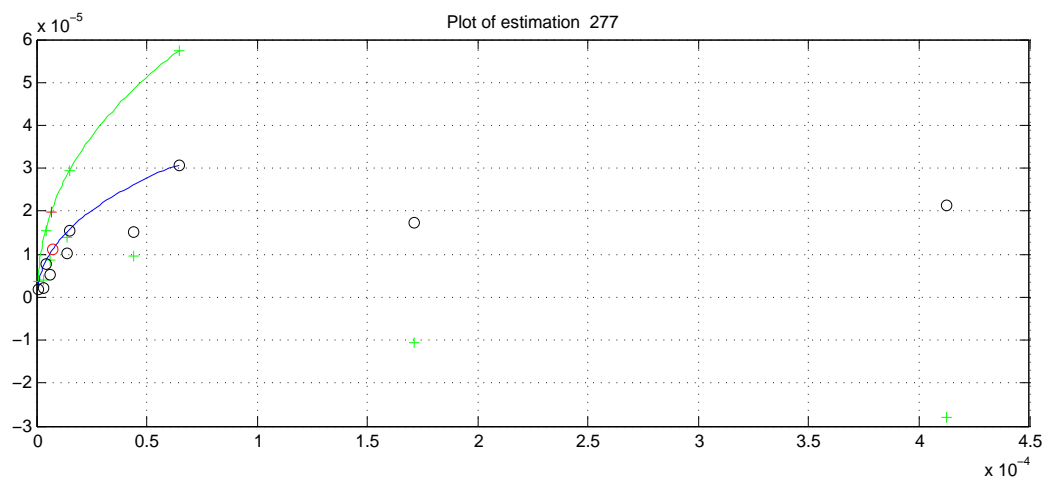

Figura 5.18: Fronteira eficiente da previsão 277.

Sem dúvida houve uma melhora considerável em relação à carteira de mercado nas quatro previsões do modelo. Não obstante, não temos a expectativa de que o modelo GARCH possa gerar visões, cujas carteiras resultantes tenham sempre desempenho superior. Tal expectativa careceria de razoabilidade. É possível que em algumas previsões o desempenho da carteira seja inferior à carteira de mercado, sem tirar o mérito do modelo de fazer boas previsões. Entretanto, o que seria desejável observar é que, em média, o resultado fosse superior ao da carteira de mercado, fato que pudemos constatar em nos resultados das previsões do modelo. Sobretudo, à luz das considerações sobre superar a carteira de mercado, acreditamos que o modelo fora capaz de captar adequadamente a dinâmica dos retornos sob os aspectos de seus fatos estilizados e, por esta razão, as carteiras geradas tiveram melhor desempenho.

Para fins desta dissertação, montamos uma estrutura que permite o funcionamento conjunto dos modelos aqui estudados e, para a estimação dos parâmetros do modelo, utilizamos 274 observações, que somadas às 4 últimas observações utilizadas para verificar o resultado do modelo, totalizam as 278 observações disponíveis até a conclusão deste trabalho. Pretende-se, entretanto, verificar de forma contínua, semana a semana, a capacidade do modelo GARCH para gerar visões de curto prazo no contexto do modelo Black-Litterman, à medida que mais dados das séries em estudo estiverem 


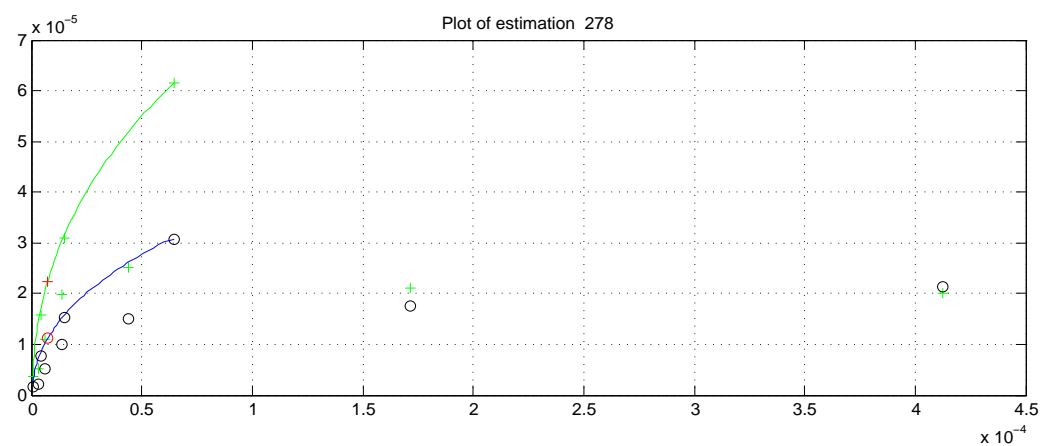

Figura 5.19: Fronteira eficiente da previsão 278.

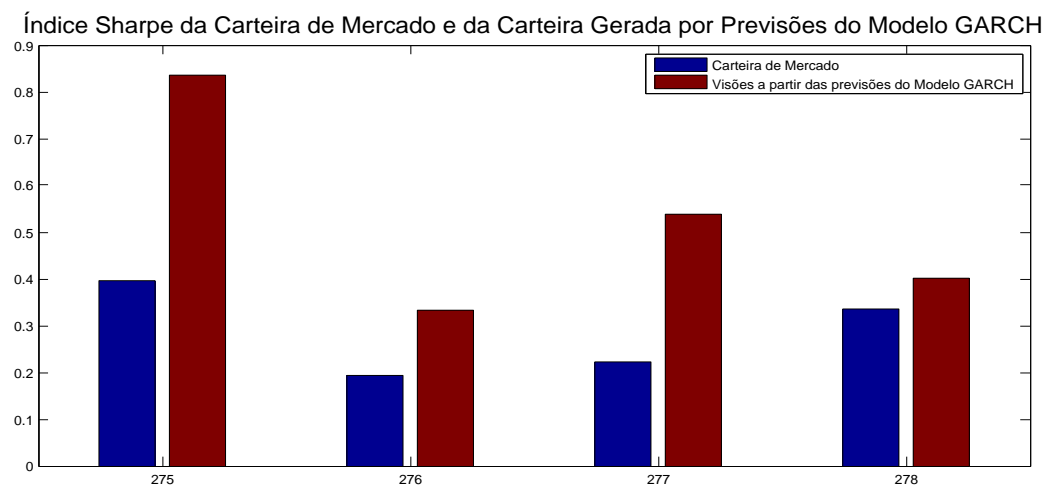

Figura 5.20: Indice Sharpe das carteiras geradas por um modelo GARCH e da carteira de mercado.

disponíveis. Isto permitirá ampliar o conhecimento a respeito dos modelos e das séries temporais de títulos de renda-fixa. 


\section{Capítulo 6}

\section{Conclusões}

O resultado do modelo Black-Litterman, além de coerente com aquilo que se propõe a fazer, traz possibilidades úteis e adequadas para gestores de dívida e gestores de carteiras, na medida em que permite expressar visões subjetivas e provê uma estrutura estatística para combinar informações quantitativas e subjetivas de forma consistente. Em particular, para o mercado de renda-fixa, que intrinsecamente possui uma relevante componente atribuída a visões e interpretações subjetivas, tais como, por exemplo, na formação de expectativas sobre a condução das políticas monetária e fiscal, o modelo se faz particularmente atrativo. O modelo resolve também os problemas decorrentes da aplicação direta dos modelos de média-variância tradicionais, como o modelo de Markowitz, uma vez que permite ao investidor assumir risco exclusivamente em posições sobre as quais tenha visões a respeito, mantendo os demais ativos em proporções neutras, isto é, em linha com a carteira de mercado, tornando o modelo mais estável e seus resultados mais coerentes com a intuição econômica. Seu resultado é composto por visões do investidor e da carteira de equilíbrio de longo prazo. Os resultados apresentados na Sessão 5.2.1 atestam todas essas propriedades. Nesta sessão apresentamos como expressar as visões, os resultados do modelo Black-Litterman, e fizemos considerações a respeito da coerência de seus resultados. Assim sendo, acreditamos ter atingido o objetivo de realizar uma aplicação que alie métodos quantitativos com intuição, de uma forma estatisticamente coerente.

Quanto à estimação de parâmetros, a aplicação de séries temporais realizada na Sessão 5.1 dos modelos propostos no Capítulo 4 se mostraram adequadas para a carteira em estudo, muito embora, conforme observado em 5.1.2, para uma melhor estimação teria sido necessário excluir algumas séries ou lançar mão do método exposto na Sessão 4.3 sobre vários fatores de risco. Alexander(2006) [Ale01b]também encontrou dificuldades para aplicar o método ortogonal em séries menos correlacionadas com o restante do sistema. Feita esta importante ressalva, o modelo foi capaz de estimar a matriz de covariâncias de uma carteira composta por dez ativos, a partir da estimação da variância de apenas quatro componentes principais, fazendo com que o modelo tenha se mantido computacionalmente bastante simples, mesmo para uma carteira com tantos ativos. Interessante pensar que se tivéssemos mais ativos(15, 30 ou mais), o número de componentes, muito provavelmente, se manteria o mesmo. Portanto, para gestores de dívida que tipicamente se defrontam com estruturas a termo, o modelo se apresenta como uma solução viável para gerar as matrizes de covariâncias do sistema, seja para utilizá-las em aplicações semelhantes à proposta no presente trabalho, seja para realizar outras medidas de risco, tal como o VaR, ou qualquer outra medida de interesse. Para as vantagens do GARCH ortogonal em relação ao EWMA do JP Morgan, ver Alexander(2001) [Ale01b].

Por último, além de estimar matrizes de covariâncias, este trabalho propôs a utlização do modelo GARCH também para gerar visões de curto prazo para títulos de renda fixa. O exercício realizado na Sessão 5.2.2 apresentou bons resultados, o que traz perspectivas positivas para esta aplicação do modelo GARCH, apesar das dificuldades apontadas para se superar a carteira de mercado. Beach e Orlov(2006) [Ste] testaram a capacidade do modelo GARCH para gerar visões sobre ativos no mer- 
cado internacional, também chegando a resultados positivos. Com isso, atingiu-se um dos objetivos deste trabalho de realizar uma aplicação do modelo Black-Litterman com parâmetros cujas estimações sejam coerentes com a natureza das séries em estudo, fato que nem sempre ocorre na aplicação do modelo Black-Litterman. O modelo GARCH, além de, obviamente, levar em consideração a natureza heterocedástica da série, é reconhecidamente uma ferramenta capaz de captar a dinâmica da evolução de séries financeiras em seus diversos aspectos, e os bons resultados reforçam esta visão.

Por último, acreditamos ter atingido o objetivo de apresentar a gestores de dívida uma ferramenta capaz de estimar o risco de uma carteira, expressar suas visões de forma consistente para construir sua carteira de referência (benchmark). Da mesma forma, oferecer a investidores uma ferramenta que seja capaz de otimizar a gestão de carteiras com grande número de ativos financeiros.

\subsection{Sugestões para Pesquisas Futuras}

Como sugestão para pesquisa de temas relacionados a esta dissertação, sugerimos algumas frentes de trabalho:

- 1. Verificar o desempenho do GARCH ortogonal fazendo ortogonalização com componentes independentes.

- 2. Testar o modelo para outras frequências de dados.

- 3. Testar o modelo de forma contínua e verificar seu desempenho em prazos mais longos, conforme sugerido no último parágrafo da Sessão 5.2.3. 


\section{Apêndice A}

\section{Parâmetros da distribuição posteriori do modelo Black-Litterman}

Construção da distribuição priori e obtenção de seus parâmetros, seguindo as hipóteses introduzidas no Capítulo 2:

$P(E(r) / \Pi)=\frac{k \exp \left\{-\frac{1}{2}(\Pi-E(r))^{\prime}(\Sigma \tau)^{-1}(\Pi-E(r))-\frac{1}{2}(P E(r)-Q)^{\prime}(\Omega)^{-1}(P E(r)-Q)\right\}}{P(\Pi)}$

Sendo: $k=\frac{1}{|2 \pi \tau \Sigma|^{1 / 2}} \frac{1}{|2 \pi \Omega|^{1 / 2}}$

E fazendo:

$$
P(E(r) / \Pi)=\frac{k \exp \left(-\frac{1}{2} \Phi\right)}{P(\Pi)}
$$

Temos:

$$
\begin{aligned}
\Phi & =E(r)^{\prime}(\tau \Sigma)^{-1} E(r)-2 \Pi(\tau \Sigma)^{-1} E(r)+\Pi^{\prime}(\tau \Sigma)^{-1} \Pi+E(r)^{\prime} P^{\prime} \Omega^{-1} P E(r) \\
& -2 Q^{\prime} \Omega^{-1} P E(r)+Q^{\prime} \Omega^{-1} Q \\
& =E(r)^{\prime}\left((\tau \Sigma)^{-1}+P \Omega^{-1} P\right) E(r)+Q^{\prime} \Omega^{-1} Q+\Pi^{\prime}(\tau \Sigma)^{-1} \Pi \\
& \left.-2\left(\Pi^{\prime}(\tau \Sigma)^{-1}+Q^{\prime} \Omega^{-1} P\right)\left((\tau \Sigma)^{-1}+P^{\prime} \Omega^{-1} P\right)^{-1}\left((\tau \Sigma)^{-1}+P^{\prime} \Omega^{-1} E(r)\right)\right) \\
& =E(r)^{\prime}\left((\tau \Sigma)^{-1}+P \Omega P\right)\left((\tau \Sigma)^{-1}+P^{\prime} \Omega^{-1} P\right)^{-1}\left((\tau \Sigma)^{-1}+P \Omega^{-1} P\right) E(r)+Q^{\prime} \Omega^{-1} Q+\Pi^{\prime}(\tau \Sigma)^{-1} \Pi \\
& \left.-2\left(\Pi^{\prime}(\tau \Sigma)^{-1}+Q^{\prime} \Omega^{-1} P\right)\left((\tau \Sigma)^{-1}+P^{\prime} \Omega^{-1} P\right)^{-1}\left((\tau \Sigma)^{-1}+P^{\prime} \Omega^{-1} E(r)\right)\right)
\end{aligned}
$$

Seja:

$$
\begin{aligned}
H & =(\tau \Sigma)^{-1}+P^{\prime} \Omega^{-1} Q \\
A & =Q^{\prime} \Omega^{-1} Q+\Pi^{\prime}(\tau \Sigma)^{-1} \Pi \\
N & =(\tau \Sigma)^{-1} \pi+P^{\prime} \Omega^{-1} Q
\end{aligned}
$$


Temos:

$$
\begin{aligned}
\Phi & =E(r)^{\prime} H^{\prime} H^{-1} H E(r)-2 N^{\prime} H^{-1} H E(r)+A \\
& =\{E(r)^{\prime} H^{\prime} H^{-1} H E(r)-\underbrace{N^{\prime} H^{-1} H E(r)}_{=E(r)^{\prime} H^{\prime} H^{-1} N}-N^{\prime} H^{-1} H E(r)+N^{\prime} H^{-1} N\}-N^{\prime} H^{-1} N+A \\
& =\left(E(r)^{\prime} H^{\prime} H^{-1}-N^{\prime} H^{-1}\right)(H E(r)-N)+A-N^{\prime} H^{-1} N \\
& =(E(r)^{\prime} \underbrace{H^{\prime}}_{=H} H^{-1}-N^{\prime} \underbrace{H^{-1}}_{=\left(H^{-1}\right)^{\prime}}) H\left(E(r)-H^{-1} N\right)+A-N^{\prime} H^{-1} N \\
& =\left(E(r)-H^{-1} N\right)^{\prime} H\left(E(r)-H^{-1} N\right)+\left[A-N^{\prime} H^{-1} N\right]
\end{aligned}
$$

$\left[A-N^{\prime} H^{-1} N\right]$ desaparece como constante na integração em E(r)

Assim:

$$
P(E(r) / \Pi) \propto \exp \left\{-\frac{1}{2}\left(E(r)-H^{-1} N\right)^{\prime} H\left(E(r)-H^{-1} N\right)\right\}
$$

Desta forma, a média de $E(R) / \Pi$ é $H^{-1} N$ e variância $H$.

Reescrevendo, a média da distribuição posteriori é $\left.\left[(\tau \Sigma)^{-1}+P^{\prime} \Omega^{-1} P\right)\right]^{-1}\left[(\tau \Sigma)^{-1} \pi+P^{\prime} \Omega^{-1} Q\right]$ e a variância: $\left.\left[(\tau \Sigma)^{-1}+P^{\prime} \Omega^{-1} P\right)\right]^{-1}$, conforme anteriormente apresentado na Equação (2.12). 


\section{Apêndice B}

\section{Transformação para $\Omega$ não Diagonal}

Conforme posto por He e Litterman(1999) [Bla99], a matriz $\Omega$ não precisa ser necessariamente diagonal, pois a matriz $\Omega$ pode ser decomposta em $V \hat{\Omega} V^{-1}$, em que $\hat{\Omega}$ é diagonal. Para tanto, as visões expressas na Equação 2.8 também sofrerão transformações, de tal forma a termos uma matriz $\hat{\Omega}$ diagonal, da seguinte forma: $\hat{P} \mu=\hat{Q}+\hat{\epsilon}^{v}$. Sendo $\hat{P}=V^{-1} P$ e $\hat{Q}=V^{-1} Q$. 
APÊNDICE B 


\section{Referências Bibliográficas}

[Ale01a] Carol Alexander. A Primer on the Orthogonal GARCH Model. Relatório técnico, ISMA Centre, University of Reading, 2001. 19

[Ale01b] Carol Alexander. Mastering Risk Volume 2 - Orthogonal GARCH. Financial Times Management, primeira edição, 2001. 41

[Alv09] Luiz Fernando Alves. Composição Ótima da Dívida Pública Brasileira: uma estratégia de longo prazo. http://www.tesouro.fazenda.gov.br/, 2009. 9

[Anb] Anbima. Índice de Duração Constante - Metodologia. http://www.anbima.com.br/idka/arqs/ metodologia-idka.pdf/. 10

[Bla92] Black F. and Litterman R. Portfolio Optimization. Financial Analyst Journal, páginas 28-43, 1992. iii, $1,3,4,5$

[Bla99] Black Litterman and Guangliang He. The Intuition Behind Black-Litterman Model Portfolios. 1999. 5, 6, 45

[Bob03] Bob Litterman and the Quantitative Resources Group. Modern Investment Management - An Equilibrium Approach. John Wiley and Sons,Inc, 2003. 4

[Dro01] Wolfgang Drobetz. How to Avoid the Pitfalls in Portfolio Optimization? Putting the BlackLitterman Approach at Work. FINANCIAL MARKETS AND PORTFOLIO MANAGEMENT, páginas 59-75, Volume 15,2001. 3, 5

[Eng01] Engle R.F., Ng. V. and Rothschild, M. Asset pricing with a factor ARCH covariance structure: Empirical estimates for treasury bills. Journal of Econometrics, páginas 213-238, Vol.45, 2001. 17

[Man06] Charlotta Mankert. The Black-Litterman Model - mathematical and behavioral finance approaches towards its use in practie. Dissertação de Mestrado, Stockholm, Sweden, Royal Instute of Technology, 2006. 5

[Mar52] Harry Markowitz. Portfolio Selection. The Journal of Finance, 7:77-91, 1952. iii, vii, 1, 3

[Mic89] Richard O. Michaud. The Markowitz Optmization Enigma: Is 'Optmized' Optimal? Financial Analysts Journal, páginas 31-41, 1989. 3

[Mor11] Pedro A. Morettin. Econometria Financeira. Blucher, segunda edição, 2011. 11, 20,21

[Ped06] Pedro A. Morettin and Clélia M. C. Toloi. Análise de Séries Temporais. Edgard Blücher, segunda edição, 2006. 26

[Sha07] William F. Sharpe. Investors and Markets. Princeton University Press, terceira edição, 2007. 36

[Ste] Steven L. Beach and Alexei G. Orlov. An Application of the Black-Litterman Model with EGARCHM-Derived Views for International Portfolio Management. 35, 41

[Ste00] Stephen Satchell and Alan Scowcroft. A demystification of the Black-Litterman model: Managing quantitative and traditional portfolio construction, 2000. 6

[Wal09] Jay Walters. The Black-Litterman Model in Detail. http://www.blacklitterman.org/, 2009. 5

[Wil01] Wilmott. Carol Alexander's The Exorcist. http://www.wilmott.com/, 2001. 18, 19 


\section{Índice Remissivo}

área do trabalho

Modelo Black-Litterman, 3

Ajuste do modelo GARCH, 25

Black-Litterman, 33

Componentes Principais, 23

Estimação GARCH, 20

Estrutura, 4, 18

Introdução, 4, 17

Metodologia, 9

Modelo GARCH Ortogonal, 23

Motivacao, 9

O Modelo, 4

O Modelo Markowitz de Média-Variância, 3

Resultados, 36

Series Temporais, 10

Vários Fatores de Risco, 19

visoesgarchortogonal, 35

visoessubjetivas, 33 